Proc. Indian Acad. Sci., Vol. C 2, part 1, May 1979, pp. 215-242. (C) Printed in India.

\title{
A review of hybrid rockets: present status and future potential
}

\author{
H S MUKUNDA, V K JAIN and P J PAUL \\ Department of Aeronautical Engineering, Indian Institute of Science, \\ Bangalore 560012
}

MS received 18 March 1978

\begin{abstract}
This paper discusses the potential of the hybrid rocket engine as a viable and attractive mode of propulsion for both space vehicles and missiles. Research and development work on this engine in other countries is presented and evaluated. The various advantages of a hybrid engine over solid and liquid engines and its problems are highlighted. It has been argued that because of the low technology needed in the development of the hybrid system, it constitutes a cost-and-time-effective propulsion system for several applications in space programmes as well as weapon systems. In support of this conclusion, experience on the developmental studies of a variable thrust $100 \mathrm{~kg}$ engine is presented. Some future possibilities for hybrid propulsion systems are cited.
\end{abstract}

Keywords. Rocket propulsion; hybrid rocket engines; hypergolic fuels; storable rockets.

\section{Introduction}

The task of propelling space vehicles and certain weapon systems is best accomplished by using rocket engines which, in addition to carrying their own oxidiser (and thus making the propulsion independent of ambient atmosphere), provide a high energy system. Every rocket engine can be viewed as consisting of two parts; a combustion chamber and a nozzle. The combustion chamber is responsible for producing hot gases at high pressure. The nozzle essentially converts the thermal energy into kinetic energy and expels gases at high velocity (of the order of $2-3 \mathrm{~km} / \mathrm{s}$ ). The increased momentum of the exhaust gases produces thrust.

Rocket engines can be classified into solid, liquid and hybrid types. Figures 1a, b, $c$ and $d$ show the schematic of the various engines. The solid rocket engine (figure 1a) comprises a solid propellant of prescribed geometry loaded into the combustion chamber to which is attached a nozzle. The propellant is a homogeneous or heterogenous mixture of a fuel and an oxidiser so put together as to result in a mechanically ' good' solid. The propellant is inhibited by a plastic sheet which is chemically bonded along all the surfaces where burning is not desired. An igniter which is capable of (remote) electrical initiation is used to start the rocket engine. It is apparent that the solid rocket engine is simple, barring the making of the propellant which itself involves high technology.

The liquid rocket engine on the other hand is far more complicated as seen from figures $1 \mathrm{~b}$ and $1 \mathrm{c}$. It consists of a feed system and a thrust chamber. The feed system has a tankage for storing liquid fuel and oxidiser separately, and a bottle containing high pressure gas regulated to proper level in the tanks for expelling the 
(a)

(b)

(c)

(d)

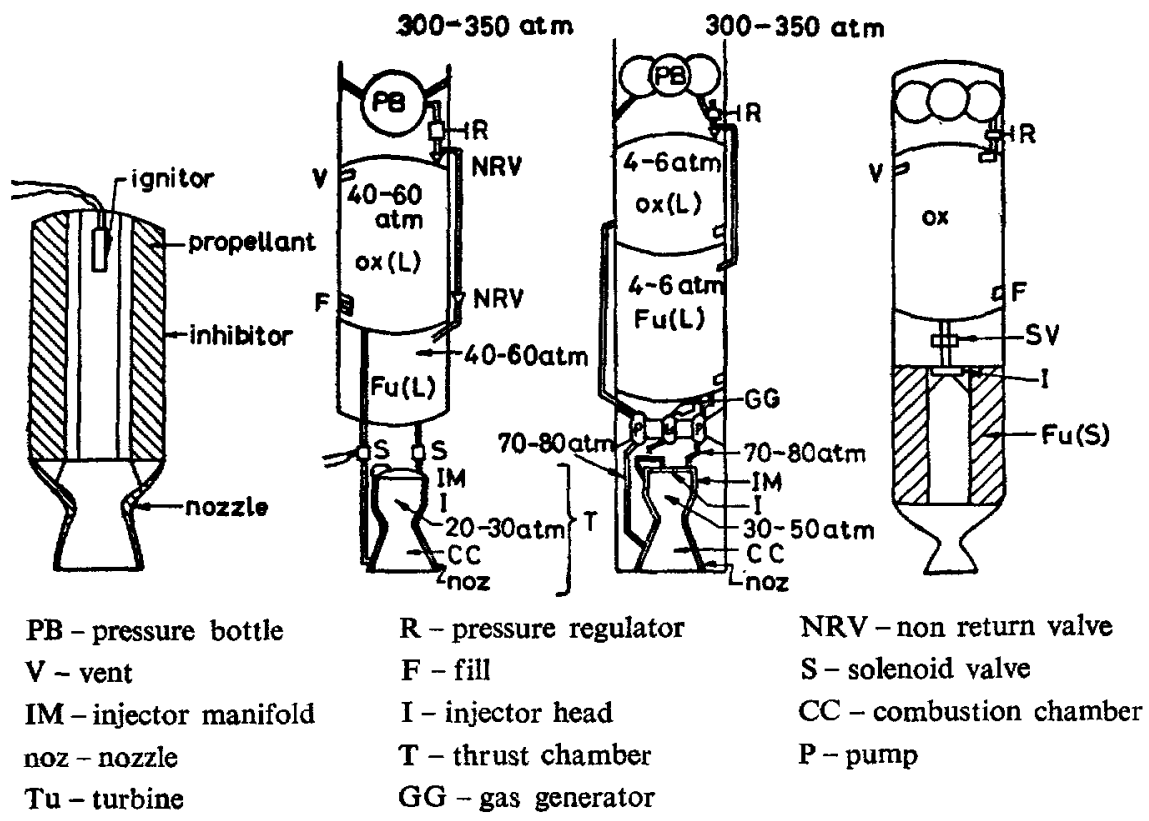

Figure 1. Schematic of the various propulsion systems. a. Solid rocket engine. b. Liquid rocket engine (pressure-fed). c. Liquid rocket engine (pump-fed). d. Hybrid rocket engine.

liquids into the thrust chamber. The thrust chamber has a combustion chamber with an injection head and manifold (for propellants) fixed to one end and the nozzle to the other. The injection head has a large number of tiny holes (as many as $\mathbf{2 0 0 0}$ -3000 ) through which the propellants are injected. In some systems like the ones shown in figures $1 \mathrm{~b}$ and $1 \mathrm{c}$, one of the propellants is circulated around the thrust chamber to cool the walls.

In large thrust engines, the feed system will have pumps driven by a turbine which itself is powered by high pressure gases derived from a gas generator (figure 1c).

A hybrid rocket engine appears to be midway between the solid and liquid engines in complexity. It uses a solid fuel and a liquid oxidiser. The combination involving a liquid fuel and a solid oxidiser is also theoretically possible, but is rarely used since the solid oxidisers are all crystalline powders and are difficult to obtain in an acceptable form. The liquid oxidiser is stored in a tank and forced through an injector into the combustion chamber containing the fuel block of specified geometry (see figure 1d). Thus the hybrid engine has a combustion chamber containing the fuel as in a solid rocket, and a tank containing the liquid oxidiser as in a liquid rocket.

\subsection{Performance parameters}

The propulsion system may be viewed as imparting to the vehicle a velocity increment (Tischler 1964)

$$
\Delta v=g I_{\mathrm{sp}} \ln \left(1+W_{\mathrm{p}} / W_{s}\right)
$$


where $g$ is the acceleration due to gravity, $W_{s}$ is the structural weight, $W_{p}$ is the propellant weight $\left(=V_{p} \rho_{p}, V_{p}=\right.$ volume of the propellant and $\rho_{p}=$ density of the propellant), and $l_{\mathrm{sp}}$ is the specific impulse, which is defined as the impulse per unit weight of the propellant, and can also be viewed as the thrust per unit weight flow rate.

If we now ask which engine type is more efficient for producing a given $\triangle 0$, we get the answer that $I_{\mathrm{sp}}$ should be large for boosters for which $W_{p}>W_{s}$ and $\rho_{p} I_{\mathrm{sp}}$, the density impulse, should be large for sustainers for which $W_{p} \ll W_{s}$.

Thus we should examine the values of specific impulse $\left(I_{\mathrm{sp}}\right)$ and density impulse $\left(\rho_{p} I_{\mathrm{sp}}\right)$ in order to assess the quality of any propellant combination or propulsion system. Large values of achieved $I_{\mathrm{sp}}$ imply less propellant to be carried, and large values of $\rho_{p} I_{s p}$ imply less inert weight to carry the same propellant weight. In general it is not possible to obtain propellants with large values of both $I_{\mathrm{sp}}$ and $\rho_{p} I_{\mathrm{sp}}$ (compare, for instance, UDMH-RFNA and $\mathrm{LOX}-\mathrm{LH}_{2}$ systems in table 1). In such cases other vehicle features determine the selection of the propellant system.

Table 1. Performance of different propellants

\begin{tabular}{|c|c|c|c|c|}
\hline Propellant & $\underset{1000 \rightarrow 14.7 \mathrm{psi}}{I_{\mathrm{sp}}}$ & $\begin{array}{c}\rho_{p} \\
(\mathrm{~g} / \mathrm{s})\end{array}$ & $\stackrel{I_{\mathrm{sp}} \rho_{p}^{p}}{(\mathrm{~s}, \mathrm{~g} / \mathrm{cc})}$ & $\begin{array}{l}\text { Opt } \\
\text { O/F }\end{array}$ \\
\hline \multicolumn{5}{|l|}{ Solid } \\
\hline $\begin{array}{l}65 \% \text { ammonium perchlorate }(1) \\
+15 \% \text { CTPB }+ \text { aluminium } \\
65 \% \text { ammonium perchlorate } \\
15 \% \text { PBAN + aluminium }\end{array}$ & $\begin{array}{l}266 \\
260\end{array}$ & $\begin{array}{l}1 \cdot 7 \\
1 \cdot 7\end{array}$ & $\begin{array}{l}452 \cdot 2 \\
442\end{array}$ & \\
\hline \multicolumn{5}{|l|}{ Liquid } \\
\hline $\begin{array}{l}\text { RFNA-UDMH } \\
\mathrm{N}_{2} \mathrm{O}_{4}-\mathrm{UDMH}^{(2)} \\
\mathrm{LOX}^{(2)} \text {-erosene }^{(2)} \\
\mathrm{LOX}-\mathrm{LH}_{2}{ }^{(2)}\end{array}$ & $\begin{array}{l}267 \\
274 \\
286 \\
366 *\end{array}$ & $\begin{array}{l}1 \cdot 22 \\
1 \cdot 14 \\
1 \cdot 01 \\
0 \cdot 26\end{array}$ & $\begin{array}{r}325 \cdot 7 \\
312 \cdot 4 \\
288 \cdot 9 \\
95 \cdot 0\end{array}$ & $\begin{array}{l}2 \cdot 6 \\
2 \cdot 1 \\
2 \cdot 1 \\
3 \cdot 5\end{array}$ \\
\hline Hybrid & & & & . \\
\hline RFNA-rubber & 260 & $1 \cdot 2$ & 312 & $4 \cdot 0$ \\
\hline RFNA-R005 & 250 & $1 \cdot 2$ & 300 & $3 \cdot 8$ \\
\hline LOX $-80 \%$ rubber $+20 \% \mathrm{Al}$ & 292 & $1 \cdot 16$ & 340 & 1.85 \\
\hline LOX-SBR & 292 & 1.09 & $318 \cdot 3$ & $2 \cdot 2$ \\
\hline $\begin{array}{l}\text { LOX }-20 \% \mathrm{Al}+80 \% \mathrm{SBR} \\
\text { LOX }-20 \% \mathrm{Al}+20 \% \mathrm{AP}\end{array}$ & 291 & $1 \cdot 14$ & $331 \cdot 7$ & $1 \cdot 8$ \\
\hline$+60 \%$ SBR & 286 & $1 \cdot 2$ & $343 \cdot 2$ & $1 \cdot 3$ \\
\hline
\end{tabular}

(1) Mastroli \& Kluger 1967; (2) Kit \& Evered 1960. *Expansion $500 \rightarrow 14 \cdot 7$ psi

Abbreviations

$\begin{array}{ll}\text { Al } & \text { Aluminium } \\ \text { CTPB } & \text { Carboxy terminated polybutadiene } \\ \mathrm{LH}_{2} & \text { Liquid hydrogen } \\ \mathrm{LOX} & \text { Liquid oxygen } \\ \mathrm{N}_{2} \mathrm{O}_{4} & \text { Nitrogen tetroxide }\end{array}$

PBAN Polybutyl acrylo nitrile

RFNA Red fuming nitric acid SBR Styrene butadiene rubber

UDMH Unsymmetrical dimethyl hydrazine

Proc. $(\mathrm{C})-5$ 


\section{Comparative evaluation}

\subsection{Performance}

Table 1 shows the values of $I_{\mathrm{sp}}, \rho_{p}, \rho_{\mathrm{p}} I_{\mathrm{sp}}$ and $(O / F)_{\mathrm{opt}}$ for a number of propellant combinations. $(O / F)_{\text {opt }}$ is the weight ratio of the oxidiser-to-fuel needed to obtain maximum specific impulse. The propellant combinations shown in the table represent those either already available or contemplated in our country.

It is clear from the table that solid engines have generally a lower specific impulse compared to liquid engines. The higher density of composite solid propellant is due to the high single crystal density of ammonium perchlorate.

Higher density in the case of hybrids is achieved by using higher loading of aluminium powder without any loss in specific impulse. It must be brought out that addition of aluminium powder increases the $I_{\mathrm{sp}}$ of solid propellants, but causes marginal variation in $I_{\mathrm{sp}}$ in the case of hybrids.

One of the reasons for this feature is the presence of the relatively heavy chlorine element in the solid propellant. Calculations on PVC-oxygen hybrid show that the peak performance $\left(I_{\mathrm{sp}}\right)$ does increase with the addition of aluminium as in the case of solids confirming the above observation.

The storable liquid combination like RFNA-UDMH is matched in performance by RFNA-hydrocarbon where the hydrocarbon could be any of the polymers like polyethelene, polybutadiene, polystyrene, polyisoprene (natural rubber) or their combinations. The LOX-kerosene semi-cryogenic liquid system is the cheapest in terms of cost of propellant per unit weight. This combination has no equivalent in solids, but is matched by the hybrid LOX-rubber, both in terms of economics and performance.

\subsection{Other features}

Table 2 shows a largely self-explanatory comparison of the three propulsion systems; but a few points need further discussion.

One of these concern the logistics of handling and transportation; hybrids appear distinctly superior to solids and marginally better compared to liquids. The transporttation of the solid propellant, particularly in large sizes, poses serious difficulties since the propellant is structurally sensitive to vibration. Since the solid 'fuel ' in a hybrid engine has very little or no oxidisers or other non-polymeric substances imbedded in it, it is highly elastomeric and can stand much greater vibration.

Another important point concerns the problem of high frequency combustion instability. Early solid rocket engines encountered little or no problem with this mode of instability. In recent times, however, (see Karnesky \& Colucci 1975), the problem is significant; high frequency instability (frequencies upto $5-6 \mathrm{kHz}$ and amplitudes of about $2-10 \%$ of mean pressure) appears to be present in the existing weapon systems.

Liquid engines, particularly of large thrust, have almost always shown up highfrequency instability during their development. And their suppression is very expensive both in terms of the costs incurred and the time spent. Hybrid engines, on the other hand, have not shown any high frequency instability even in large thrust ratings $(\sim 10-18$ tonnes, Ordahl \& Bae 1965). 
Table 2. A comparison of various characteristics of the propulsion systems

\begin{tabular}{|c|c|c|c|}
\hline Characteristic & Solid & Liquid & Hybrid \\
\hline Ignition & $\begin{array}{l}\text { Use of an } \\
\text { igniter }\end{array}$ & $\begin{array}{l}\text { No igniter for } \\
\text { hypergolic comb- } \\
\text { ination. Other- } \\
\text { wise necessary }\end{array}$ & Same as in (ii) \\
\hline Thrust modulation & 一 & Excellent & $\begin{array}{l}\text { Excellent } \\
\text { upto } 10: 1\end{array}$ \\
\hline Simplicity & Simple & Very involved & Between (i) and (ii) \\
\hline Possibility of explosion & High & Low & Very low \\
\hline $\begin{array}{l}\text { Logistics of transportation } \\
\text { and handling, for large } \\
\text { sizes particularly }\end{array}$ & Poor & Excellent & Excellent \\
\hline $\begin{array}{l}\text { Combustion instability. Low } \\
\text { frequency instability }\end{array}$ & 一 & $\begin{array}{l}\text { Poor/can be } \\
\text { resolved }\end{array}$ & $\begin{array}{l}\text { Poor/can be } \\
\text { resolved }\end{array}$ \\
\hline $\begin{array}{l}\text { High Frequency/acoustic } \\
\text { instability }\end{array}$ & $\begin{array}{l}\text { Not insignifi- } \\
\text { cant }\end{array}$ & Very difficult & Not observed at all \\
\hline On-off operation & - & Excellent & Fair \\
\hline Reliability & Good & Fair & Fair \\
\hline Propellant utilisation & $96-98 \%$ & $96-98 \%$ & $96-98 \%$ \\
\hline$O / F$ & $\begin{array}{l}\text { Tuned by the mix- } \\
\text { ture ratio used ini- } \\
\text { tially during mix- } \\
\text { ing. Remains con- } \\
\text { stant throughout } \\
\text { combustion. }\end{array}$ & $\begin{array}{l}\text { Is maintained about } \\
\text { same throughout the } \\
\text { combustion chamber } \\
\text { by using large num- } \\
\text { ber of injection holes } \\
\text { constant during } \\
\text { combustion. }\end{array}$ & $\begin{array}{l}\text { Is large at injector } \\
\text { and decreases along } \\
\text { the combustion cham- } \\
\text { ber towards the nozzle. } \\
\text { It varies during com- } \\
\text { bustion. This could be } \\
\text { a serious problem and } \\
\text { needs proper design of } \\
\text { grain geometry. }\end{array}$ \\
\hline $\begin{array}{l}\text { Initial temperature }\left(T_{m}\right) \\
\text { dependence of performance }\end{array}$ & $\begin{array}{l}\text { The burning rate } \\
\text { strongly depends } \\
\text { on } T_{m} \text { and this in- } \\
\text { deed is a serious } \\
\text { problem in propel- } \\
\text { lant making and } \\
\text { nozzle design. }\end{array}$ & Marginal & Marginal \\
\hline \multirow[t]{4}{*}{ Regression rate law } & $\begin{array}{l}r_{s}=a P_{c}^{n} \\
\exp \left[a\left(T_{m}-T_{m}^{o}\right)\right]\end{array}$ & & $r_{h}=a G^{m}$ \\
\hline & $\begin{array}{l}a=\text { Temperature } \\
\text { sensitivity } \\
\text { coefficient }\end{array}$ & & $\begin{array}{l}a=0.02-0.04 \text { for } \\
m=0.5\end{array}$ \\
\hline & $T_{m}^{0}=$ Reference & & \\
\hline & $\begin{array}{l}\text { temperature } \\
n=0.1-0.8 \\
a=0.002-0.1 \mathrm{~cm} / \mathrm{s}\end{array}$ & & $m=0.5-0.8$ \\
\hline
\end{tabular}




\subsection{Some mechanistic differences and consequences thereof}

The mass production rate $(\dot{m})$ in the propulsion systems considered can be written as

$$
\begin{aligned}
& \dot{m}=\rho_{p} A_{b} r_{s} \text { (solids), } \\
& \dot{m}=m_{\mathrm{OX}}+\dot{m}_{f} \text { (liquids), } \\
& \dot{m}=m_{\mathrm{OX}}+\rho_{p} A_{b} r_{h} \text { (hybrids), }
\end{aligned}
$$

where $A_{b}$ is the burning area, $\dot{m}_{\mathrm{Ox}}$ is the oxidiser flow rate, $\dot{m}_{f}$ is the fuel flow rate, $r_{s}$ is the linear burning rate and $r_{h}$ is the linear regression rate. Though the terms burning rate and regression rate both refer to the same combustion rate, the former refers generally to solid propellants where the deflagration occurs independently of external oxidiser, and the latter to hybrid fuel where the fuel regresses due to the heat flux from the diffusion flame or hot gases.

The dependence of the burning and regression rates on parameters like pressure and mass flux is governed by two processes, namely mixing and chemical reaction. We now examine the effects of these on combustion in the various systems.

2.3a. Solid propellants Since the fuel and oxidiser are finely mixed in solid propellants, the burning rate is a strong function of chemical reaction rate. Since the chemical reaction, in turn, depends strongly on pressure, (it causes the location of the flame zone to move with respect to the surface, causing difference in heat transfer) the burning rate of solid propellants depends strongly on pressure. This dependence is empirically represented for most propellants in the useful pressure range as $r_{s}=a_{s} p^{n}$ where $a_{s}$ and $n$ are constants. Typical values of $a_{s}$ and $n$ are seen in table 2. These values can be altered by introducing small amounts of chemical modifiers to the solid propellants.

The pre-mixed state of fuel and oxidiser causes the propellant to burn along all the exposed surfaces and in case any small defects such as a crack in the propellant are present, the mass production rate will become much larger than envisaged and a seriously distorted pressure time curve will result possibly even leading to a disastrous explosion.

The sensitivity of the burning rate to the presence of impurities or additives is so large that even $0.05 \%$ of an additive like lecithin (a wetting agent) may cause burning rate reduction by as much as 10\% (Thaper et al 1977). Also, the burning rate of the propellant is sensitive to the processing schedule. These imply that the quality control on the composition of the ingredient as well as the processing schedule has to be of a high order. These features make the solid propellant technology a sophisticated one.

2.3b. The liquid engine The processes in a liquid rocket engine are equally complex, if not more. The fine jets of the propellants impinge on each other, react intensely if the propellants are hypergolic or atomise to help quick vaporisation. Chemical reactions take place in the gas phase leading to generation of hot gases after the vaporised components get mixed. Amongst the processes involving mixing, vaporisation and chemical reaction, vaporisation is taken to be the ratelimiting mechanism for determining the overall parameters (like the length of a 
combustion chamber). Thus one of the important factors in the combustion chamber is droplet spray vaporisation in the hot gaseous environment. This process is essentially diffusion-controlled and so the effects of kinetics will be secondary.

Possibilities of explosion in liquid engines using hypergolic propellant combinations are generally due to improper timing of entry of fuel and oxidiser. An oxidiser lead of about 100-200 ms generally overcomes the problem. The development of high thrust engines is beset with the serious problem of combustion instability, particularly of the disastrous high frequency kind. Although the present state-of-the art permits the trying of some ad hoc solutions, removal of instabilities is considered time- and effort-consuming.

2.3c. The hybrid rocket engine The process in a hybrid rocket combustion chamber over a large portion of the chamber constitutes the diffusive combustion in the boundary layer very close to the regressing fuel surface. The initial part is

(a)

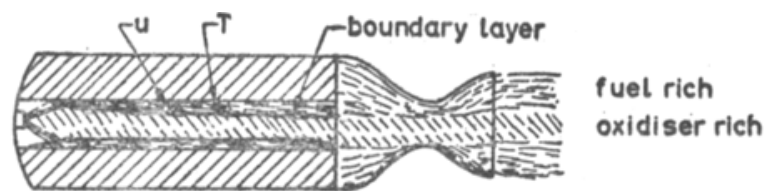

(b)

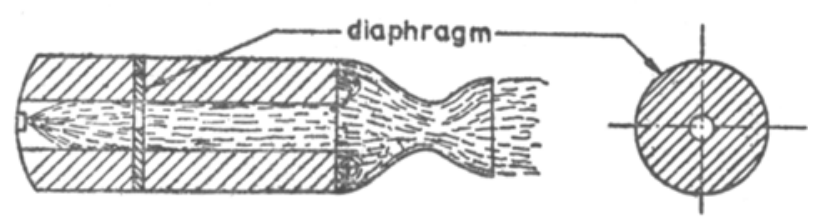

(c)

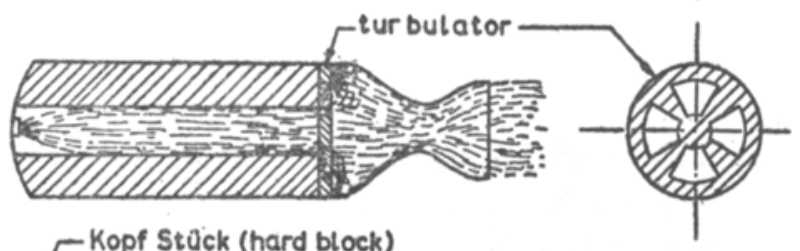

low regrassion material (graphite)

(d)

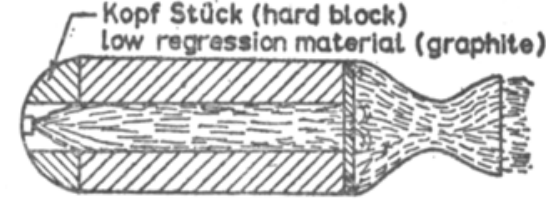

(e)

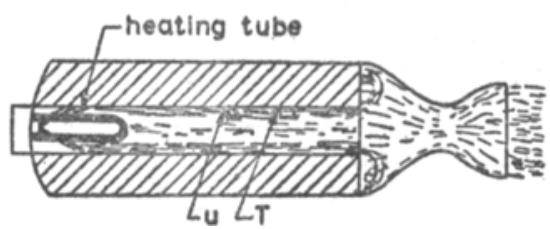

Figure 2. Different methods of increasing the performance. a. Normal hybrid having exit streams incompletely mixed. b. Improvement by French workers by using the diaphragm which not only causes intense mixing and hence better combustion efficiency, but is supposed to reduce the instability. c. The turbulator used by Swedish and US workers. It causes intense mixing and better combustion efficiency. d. Hard block at injector end is used by Schmucker and graphite blocks by UTC (USA) for reducing combustion instability. $\% e$. Heating tube inside the combustion chamber reduces instability and leads to better combustion efficiency. 
dominated by processes of impingement of the liquid oxidiser (which is sprayed by an injector) on the fuel surface and its vaporisation (see figure $2 a$ ). Since the process is essentially diffusion-dominated, chemical kinetics, and therefore pressure, have a relatively smaller effect. It is the flux of hot gases (consisting of the products of combustion and oxidiser not yet utilised) past the fuel surface which primarily affects the regression of the fuel. The regression rate law can be deduced from the boundary layer considerations as was first accomplished by Marxman \& Gilbert (1963). The law reads that $r_{h}=a G^{n}$, where $G$ is the mass flux of hot gases past the surface, $a$ and $n$ are constants; typically a $0.01-0.03 \mathrm{~cm} / \mathrm{s}$ (flux) ${ }^{n}, n=0.5$ for laminar flow and 0.8 for turbulent flow.

Now it is possible to explain some features of hybrid engines cited in table 2. First, the $O / F$ of a hybrid engine is not necessarily constant throughout the firing. Using the expression in (3) we can express $O / F$ in terms of the inner diameter of the cylindrical fuel block burning from inside outwards as

$$
O / F \simeq d^{2 n-1}\left(m_{\mathrm{ox}} / \pi\right)^{1-n} / \rho_{D} a L,
$$

where $d=$ inner diameter of the port and $I$ is the length of the fuel block. If $n=0.5$, as in the case of laminar flow, $O / F$ is a constant and does not change during the firing; and if $n=0.8$, as in the case of turbulent flow, the value of $O / F$ increases during the firing, showing that the products become oxidiser-rich. This, in fact, causes changes in the specific impulse of the system during the firing. There are ways of combating this problem (see Anon 1964). One of these is to fix the initial operating point on a slightly fuel-rich side so that when the operating point moves to the oxidiser-rich side, the specific impulse does not vary by more than 1-2\%. Another technique which maintains a constant $O / F$ level is to use two oxidiser injection points, one near the head end and the other near the aft end. In the early part of the firing the burning is fuel-rich and aft end injection is used to optimise it. During the later part of the firing the products of combustion from the end of the fuel block tend towards oxidiser-richness and so aft-end injection is reduced to maintain the same $O / F$ level.

The second feature concerns the low explosion hazard during storage, transportation and firing. That the explosion and fire hazard are small compared to that for a solid rocket is easy to appreciate because the solid rocket has the fuel and oxidiser imbedded in the same matrix whereas the hybrid has the solid fuel and liquid oxidiser separately stored. And in the event of an accidental initiation, the former can burn by itself, whereas the fuel in the hybrid rocket has to receive oxidiser for its combustion. The fire hazard of the hybrid is smaller than of liquids because, in the event of an explosion, the liquids of a liquid rocket can flow, widely spread and get mixed up, while the fuel and oxidiser in the hybrid have greater resistance to large scale mixing since the fuel is in the form of a solid.

We can further argue that a crack or a tiny hole in the fuel block of a hybrid causes little or no change in the performance, whereas the same crack or hole in a solid propellant may cause explosion. To appreciate this we notice that the regression of the fuel occurs under the action of a heat flux from the diffusion flame. Thus any area of the fuel which receives less heat flux will regress less. The tiny hole represents a zone which is farther away from the flame and hence receives less heat flux and so will regress less. This means that the tiny hole evens out instead of becoming larger as 
in a solid rocket and the perturbation due to changed mass flow becomes small as burning progresses.

The third feature concerns the sensitivity of the regression rate to the nature of fuel. It has already been noted that addition of even a small amount of some compounds can disastrously alter the burning rate of a solid propellant. The situation is quite the opposite in the case of hybrids. The regression rate is negligibly dependent on the nature of fuels, even when they are as different as polystyrene and natural rubber or polybutadiene. The reason for this lies in the counter-balancing effect called 'blowing effect'. This effect is simply that the burning rate does not linearly scale with the ratio of the input heat flux to heat of phase transformation at the surface, but less (in fact, much less) strongly dependent on it. If we invoke the heat balance at the surface of the burning fuel, we have

$$
\rho_{p} \pi_{h}=\dot{q}^{\prime \prime} /(\Delta h)_{s}
$$

where $(\Delta h)_{s}$ is the heat of phase change at the surface (including that needed for degradation) and $\dot{q}^{\prime \prime}$, the heat flux into the surface. Now, if by some mechanism $r_{h}$ increases by decrease of $(\Delta h)_{s}$, this increase in $r_{h}$ causes an increase in boundary layer thickness, hence, reduction in gradients at the surface and in heat flux. The net result is of course, an increase in regression rate but much less than is to be expected from the linear relation. This effect is so significant that a $10 \%$ increase in $\dot{q}^{\prime \prime}$ leaves $r_{h}$ virtually unaltered. Even a $35 \%$ increase in $\dot{q}^{\prime \prime}$ causes only a $10 \%$ increase in the regression rate (Marxman \& Gilbert 1963).

Similar arguments can be used to explain why the initial temperature change causes much less change in the regression rate of a hybrid fuel than in the burning rate of a solid propellant.

\subsection{Relative costs of development}

In the development of high thrust, large burn-time rocket engines, one of the important parameters would be the cost of the propellant. The relative costs of various propellant combinations prevalent in 1964 are represented in figure 3 (taken from Tischler 1964). It is clear from this that LOX-RP1 is the cheapest propellant combination. In fact, this is the reason why LOX-RP1 was chosen for Saturn I stage (F-1 engine). The relative costs of other combinations (in India) are shown in table 3. It must be noted that both UDMH and $\mathrm{N}_{2} \mathrm{O}_{4}$ are now being made only in relatively small quantities. It would be interesting to work out the cost of a typical engine. Consider a 30-ton thrust engine with a burn-time of $100 \mathrm{~s}$. Assuming the developmental effort to be equal to 30 firings of full duration, the total propellants needed would be 350-400 tons. By taking the costs in table 3 the development of a 30-ton engine would cost about Rs. 4.00 lakhs for the propellants in the case of LOX-RP1 and Rs. 320.00 lakhs for solid propellants. A typical hybrid should cost Rs. 10.00 lakhs for the propellants.

The relative cost structure of small thrust engines is dominated not only by propellants but by hardware and other developmental costs. It is not evident which propulsion system will be more efficient from this point of view. Apparently solid propellant engines will be more efficient where the specifications do not call for very large burn-time or variable thrust or stop-start capability. In cases where flexibility 


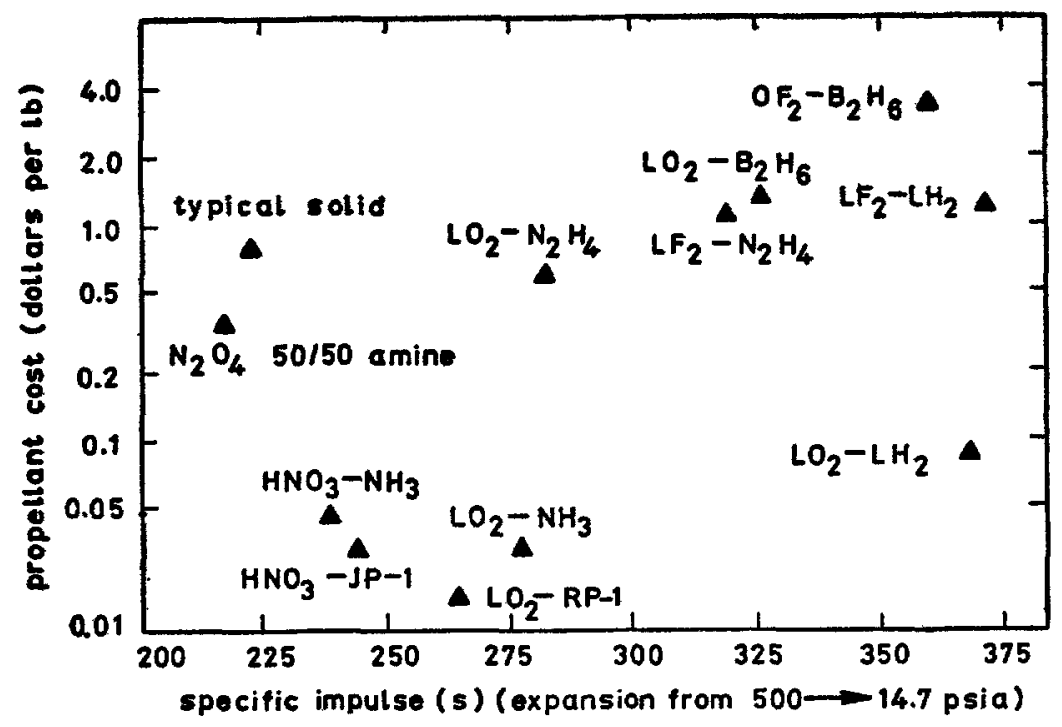

Figure 3. Relative cost of propellants from Tischler (1964).

Table 3. Relative costs of various propellants

\begin{tabular}{lll}
\hline \multicolumn{1}{c}{ Propellant } & Relative cost & \multicolumn{1}{c}{ Remarks } \\
\hline Solid propellant & $75-85$ & \\
RFNA-UDMH* & $30-35$ & Price of LOX-RP1 \\
$\mathrm{N}_{2} \mathrm{O}_{4}$-UDMH & $35-40$ & combination would \\
LOX RP1 (kerosene) & 1 & be about Re. 1 per kg \\
LOX-natural rubber & $2-3$ & \\
LOX-natural rubber- & $3-4$ & \\
$\quad$ aluminium SBR* & & \\
\hline
\end{tabular}

on the choice of thrust-time curve in the actual system is demanded, the only competitors are the liquid and hybrid engines. An assessment of the relative cost of a hybrid engine can be obtained from the studies made in the development of a variable thrust hybrid rocket engine to vary the thrust from $30 \mathrm{~kg}$ to $250 \mathrm{~kg}$ (dial-a-thrust system) at United Technology Centre, USA. It is reported that the engine utilises a common plastic material as the solid fuel and nitric oxide as the liquid oxidiser. The cost of an 18-month development programme is about one tenth of that of a conventional programme (Anon 1967).

Apparently, hybrid engines compete strongly with liquid engines even in economics - at low thrust levels. There are, however, applications like those of satellite control thrusters with the requirements of long duration storage with restart when liquid monopropellant/bipropellant engines are best suited.

\section{Work in other countries}

Though hybrid rocket engines were conceived as early as 1937 and Obert of Germany made unsuccessful attempts at making a carbon (graphite) oxygen rocket, research on 
hybrid engines was conducted only intermittently till 1960s. In fact, engines built around 1961 had a poor combustion efficiency and were of low thrust (about $100 \mathrm{~kg}$, see Ordahl 1964). The causes for poor combustion efficiency were not understood till about 1962. In fact the basic principle of combustion in hybrid rockets namely of boundary layer combustion was not understood till 1961-62. However, our understanding grew rapidly thereafter and in 1963 a 500-kg thrust high performance engine had been built (Ordahl 1964). Around this time work started in other countries also, mainly Sweden and France. France built a sounding rocket (LEX) around 1964 and Sweden built its own sounding rocket (SR-1) around 1965. The United States developed the capability to build hybrid engines in several centres-United Technology Centre (UTC), Reaction Motors Division of Thikol Chemical Corporation and Aero Jet General. Each of these (primarily UTC) had made many tests and built engines of various thrust levels right up to 18 tonnes (see table 4 for details of engines in different countries).

\subsection{Propellants used}

Table 4 indicates the various fuels and oxidisers used by different countries. A few comments on the fuels used would be in order.

Swedish workers use a fuel named Tagaform based on an amine and into which additives like lithium borohydride and lithium aluminium hydride are added in small amounts to decrease the ignition delay with red fuming nitric acid (RFNA). The ignition delay with such a system is claimed to be 2-3 ms (Magnusson 1966). This solid which is in the form of a powder is pressed into the desired shape and introduced into the motor. Apparently this is not a highly desirable technique since the pressed powder is likely to be brittle and shock-sensitive. French workers used fuels like $n$-metatoluene diamine (NMTD) and phosphoraux (phosphorous tri $n$-methylimide; see Verdier 1970), which are highly hypergolic with RFNA. The problem of obtaining good mechanical integrity was solved by incorporating $96 \%$ NMTD in $4 \%$ nylon and coating the inner surface with phosphoraux to allow quick ignition.

Workers in USA studied several propellants; the oxidisers include mixed oxides of nitrogen (mixture of $\mathrm{NO}$ and $\mathrm{NO}_{2}$ in liquid form) and a mixture of flourine and oxygen in liquid form (FLOX) and fuels include PMMA, polyethylene and polybutadiene.

Gany \& Timnat (1972) in Israel have used polyester loaded with about $10-20 \%$ of ammonium perchlorate. This fuel cannot burn by itself, but regresses at fairly high rates (nearly twice as compared to conventional fuels) when used in the motor with RFNA as the oxidiser.

\subsection{Some problems resolved}

Two important problems resolved since the early sixties deal with poor performance $\left(I_{s p}\right)$ and low frequency combustion instability.

The earlier description of the combustion process showed that burning occurs close to the fuel surface. If the oxidiser injected at the front end is now distributed over the port, the oxidiser travelling through the port does not necessarily mix with the vaporised fuel intensely (see figure 2). This implies that the stream coming out 
Table 4. The hybrid engines in other countries

\begin{tabular}{|c|c|c|c|}
\hline $\begin{array}{c}\text { Country and } \\
\text { name of engine }\end{array}$ & Engine details & Fuel/oxidiser & Remarks \\
\hline \multicolumn{4}{|l|}{ Sweden } \\
\hline $\begin{array}{l}\text { HR-4 } \\
\text { (Ankarsward 1966) }\end{array}$ & $\begin{array}{l}1.05 \mathrm{~m} \text { length } \times 0.1 \mathrm{~m} \mathrm{OD} \\
172 \mathrm{Kgf} \times 6 \mathrm{~s} \text { and } \\
34 \mathrm{Kgf} \times 10 \mathrm{~s} \\
\text { pressure-fed }\end{array}$ & $\begin{array}{l}\text { Taga-form } \\
\text {-RFNA } \\
I_{\mathrm{sp}}=240 \mathrm{~s}\end{array}$ & \multirow{2}{*}{$\begin{array}{l}\text { Flygmotors have conducted ex- } \\
\text { tensive } R \text { \& } D \text { on hypergolic } \\
\text { propellants and some on re- } \\
\text { gression rate studies. They } \\
\text { have developed successful re- } \\
\text { coverable sounding rockets on } \\
\text { this basis. }\end{array}$} \\
\hline $\begin{array}{l}\text { SR-1 } \\
\text { (Perrson 1970) }\end{array}$ & $\begin{array}{l}3.15 \mathrm{~m} \text { length } \times 0.25 \mathrm{~m} \mathrm{OD} \\
1470 \mathrm{Kgf} \times 20 \mathrm{~s} \\
\text { pressure-fed }\end{array}$ & $\begin{array}{l}\text { Taga-form } \\
\text {-RFNA } \\
\text { (hypergolic) }\end{array}$ & \\
\hline \multicolumn{4}{|l|}{ France } \\
\hline (Duban 1968) & $\begin{array}{l}0.95 \mathrm{~m} \text { length } \times 0.16 \mathrm{~m} \mathrm{OD} \\
1100 \mathrm{~kg} \times 6 \mathrm{~s} \\
200 \mathrm{~kg} \times 24 \mathrm{~s} \\
\text { pressure-fed }\end{array}$ & $\begin{array}{l}\text { Metatoluene } \\
\text { diamine in } 4 \% \\
\text { nylon-RFNA }\end{array}$ & $\begin{array}{l}\text { ONERA has made extensive } \\
\mathbf{R} \& \text { D on various aspects of } \\
\text { hybrid rockets like hypergolic } \\
\text { ignition, regression rate studies. } \\
\text { motor test, performance im- } \\
\text { provement tests, etc, }\end{array}$ \\
\hline $\begin{array}{l}\text { Sounding rocket } \\
\text { demonstration } \\
\text { system (Schrucker } \\
\text { \& Schauer 1974) }\end{array}$ & $\begin{array}{l}40 \mathrm{~kg} \times 18 \mathrm{~s} \\
\text { regeneratively } \\
\text { cooled nozzle } \\
\text { pressure-fed }\end{array}$ & $\begin{array}{l}30 \% \\
p \text {-toluidiene } \\
\text { and } 70 \% p \text { - } \\
\text { aminophenol }\end{array}$ & $\begin{array}{l}\text { Have made a fair amount of } \\
\text { research on regression rate as- } \\
\text { pects. They have also studied } \\
\text { polyethylene-FLOX systems. }\end{array}$ \\
\hline $\begin{array}{l}\text { Israel } \\
\text { Demonstration of } \\
\text { R \& D motor } \\
\text { (Gany \& Timnat } \\
1972\end{array}$ & $230 \mathrm{~kg}$ thrust & $\begin{array}{l}10 \%-20 \% \mathrm{AP} \\
\text { in polyester- } \\
\text { RFNA }\end{array}$ & $\begin{array}{l}\text { IIT (Israel) has made some } \\
\text { contribution on fundamental } \\
\text { aspects of hybrid rocket engines. }\end{array}$ \\
\hline \multicolumn{4}{|l|}{$U S A$} \\
\hline $\begin{array}{l}\text { Target drone } \\
\text { (UTC) }\end{array}$ & $3.4 \mathrm{~m}$ length $\times 0.33 \mathrm{~m} \mathrm{OD}$ & $\begin{array}{l}\text { Polybutadiene } \\
\text { (PB)+PMMA } \\
\text { +RFNA }\end{array}$ & $\begin{array}{l}\text { Most extensive } \mathrm{R} \& \mathrm{D} \text { work } \\
\text { has been completed by UTC } \\
\text { research workers. Fundamental } \\
\text { studies by Marxman \& co-wor- } \\
\text { kers and developmental tests } \\
\text { by Ordahl have been performed. }\end{array}$ \\
\hline $\begin{array}{l}\text { Upper stage } \\
\text { engine (UTC) } \\
\text { (Ordahl \& Bae } \\
\text { 1965) }\end{array}$ & $\begin{array}{l}3.73 \mathrm{~m} \text { length } \times 1.19 \mathrm{~m} \mathrm{OD} \\
\times 5443 \mathrm{~kg} \text { thrust } \\
\text { ablatively cooked } \\
\text { nozzle, pressure-fed }\end{array}$ & $\begin{array}{l}\mathrm{Li} / \mathrm{LiH} / \mathrm{PE} \\
-\mathrm{FLOX}\end{array}$ & \\
\hline $\begin{array}{l}\text { Upper stage engine } \\
\text { (Ordahl \& Bae } \\
\text { 1965) }\end{array}$ & $\begin{array}{l}18000 \mathrm{~kg} \text { thrust } \\
\text { demonstration engine }\end{array}$ & & \\
\hline $\begin{array}{l}\text { Reaction motors } \\
\text { (of Thiokol } \\
\text { Chemical Corpo- } \\
\text { ration) (Judge 1964) }\end{array}$ & $\begin{array}{l}300 \text { test firings of } \\
\text { engine diameters } \\
\text { from } 60 \mathrm{~mm}-250 \mathrm{~mm} \\
\text { at various thrust levels }\end{array}$ & $\begin{array}{l}\text { Polyurethane } \\
\text { +polybutyl } \\
\text { acrylic acid } \\
\text {-FLOX, } \\
\text { RFNA, } \mathrm{N}_{2} \mathrm{O}_{4}\end{array}$ & $\begin{array}{l}\text { The basic aspects of injector } \\
\text { design-compatibility with engine } \\
\text { combustion stability have been } \\
\text { studied. Also the feasibility of } \\
\text { obtaining high thrust levels has } \\
\text { been shown. }\end{array}$ \\
\hline Aero Jet General & $\begin{array}{l}100 \text { full-scale test firings } \\
\text { on motors from } 150 \mathrm{~mm} \\
\text { OD thrusts of } 700 \mathrm{~kg} \\
\text { to } 400 \mathrm{~mm} \mathrm{OD} \mathrm{with} \\
\text { thrusts of } 5500 \mathrm{~kg}\end{array}$ & $\begin{array}{l}\text { Polymeric fuels } \\
+ \text { metal addi- } \\
\text { tives-OF }-\mathrm{F}_{2}\end{array}$ & \\
\hline
\end{tabular}


of the nozzle is not homogeneous and there are unmixed pockets of oxidiser and fuelrich regions leading to effectively low chamber gas temperature and so, to low performance. This has been overcome by French workers by using a diaphragm (figure 2) at some location along the length. Using experimental data, guidelines for the location and geometry of the diaphragm have been developed to obtain maximum performance (see Moutet's comments on Marxman \& Woolridge 1968). In hypergolic systems, the diaphragm is supposed to suppress combustion instability as well. It is argued that the increase in stay-time in the initial region bounded by the diaphragm is responsible for the suppression of the instability.

Workers in USA and Sweden have used 'turbulators' at the aft end of the combustion chamber to cause intense mixing (figure $2 \mathrm{c}$ ). Since the reactants are in a gaseous phase at high temperatures, very small stay-times (about $100 \mu \mathrm{s}$ ) would be sufficient to cause complete combustion before the gas enters the nozzle. Experiments have shown that combustion efficiency can be raised from as low as $50-60 \%$ to $94-$ 95\% by using certain devices (Ankarsward 1966).

Combustion instability in hybrid systems occurs due to random oscillations with amplitudes varying from $2-20 \%$ (or more) of the mean pressure and frequencies upto $40 \mathrm{~Hz}$ or so. Two reasons for the instability are: (i) the poor vaporisation of the liquid oxidiser, which leads to a time-lag between the moment of injection and the moment of conversion to gas; the lag can under certain conditions lead to instability and (ii) the large heterogeneous reaction at the surface of the fuel which can occur significantly in hypergolic systems of the type used in many countries including India.

To overcome these forms of instability the parameters of operation, like pressure drop across the injector, injection characteristics and fuel composition have to be suitably altered.

Further, in hypergolic systems the relatively poor mechanical properties of the solid near the injector have been known to cause instability (Schmücker 1972). Hence improving the mechanical properties of the solid near the injector region is considered an aid to stability. Workers in Germany and at UTC use a graphite block near this injection head to improve the mechanical properties of the solid (figure 2d).

Gany \& Timnat (1972) have used a heating tube inside the port of the grain such that the oxidiser flowing in the tube gets heated before injection. The heating of the oxidiser (RFNA here) reduces the viscosity and facilitates atomisation causing faster vaporisation. It is clearly demonstrated that the use of a heating tube raises the combustion efficiency from 60 to $98 \%$ (figure 2e).

Summarising, most of the countries which have undertaken the development of hybrid rocket engines have shown the technical feasibility of developing hybrid propulsion systems with various levels of thrust and burn-time.

\subsection{Why there are no practical large hybrid systems in countries other than USA}

It is striking that hybrid engines have not been used in any large scale launch vehicle system even though they present advantages, many of which have been discussed above. Some answer to this puzzling feature may be found in the literature on the subject. A careful study of early literature reveals that the answer lies more in history rather than in technology. As mentioned earlier, promising developmental work on hybrid engines was completed around 1963-1964. It is clear that USA had developed solid/liquid engines with thrust levels far exceeding (by many orders of magnitude) 
Table 5. List of some available engines in 1963

\begin{tabular}{llll}
\hline Country & Engines/vehicles & $\begin{array}{c}\text { Thrust } \\
\text { (tons) }\end{array}$ & $\begin{array}{c}\text { Diameter } \\
\text { of the engine } \\
\text { (mm) }\end{array}$ \\
\hline France & SEPR series & $4-8$ & $230-580$ \\
UK & RZ-2 (liquid) & $62-68$ & 1130 \\
USA & $\begin{array}{l}\text { Minuteman, Polaris, Titan } \\
\text { - were either under production } \\
\text { or in advanced stage of develop- } \\
\text { ment }\end{array}$ & Upto 300 & Upto 3000 \\
\hline
\end{tabular}

that of hybrid engines (see table 5). Further, this period of history was full of fierce competition between the USA and the USSR to build engines of larger and larger thrust for military applications. This naturally led to increased investments on the already well-developed systems, so much so that adequate inputs into new propulsion systems were difficult to obtain. These aspects have been discussed by Barrere \& Moutet (1967) who state "The future of hybrid rockets as with any other propulsion system is difficult to predict because political factors interfere with technical factors. Large amounts of money have been spent to develop liquid and solid propellant rockets and it is difficult to imagine a similar effort being made now for hybrid propulsion. Yet the state of our knowledge is closely related to the amount of money spent. If, for one reason or another, rocket propulsion had begun with hybrid motors, and the money had been spent on hybrid propulsion, our present knowledge of hybrids would be at least comparable to our present knowledge of solid or liquid rocket motors. We would then be asking whether it was of interest to develop solid or liquid motors.

'But history worked out the other way. Nevertheless, that is not a valid reason to ignore hybrid rockets now. Its potential performance and its attractiveness for many applications argue persuasively for an increasing investment and a continuation of the present programme of research and development'.

An almost similar view was expressed by Nachbar (1964) while reviewing the status of hybrids in USA. "The overriding disadvantage of the hybrid system is the advanced development status of both solids and liquids'. These clearly indicate the reasons why countries other than the USA ignored further development of large thrust hybrid systems.

\section{Work at the Indian Institute of Science}

Work on hybrid rockets commenced at the Department of Aeronautical Engineering, Indian Institute of Science in mid-1973. While the initial work had the benefit of a few publications, much of what has been done is a consequence of efforts based on known fundamental physical principles. And quite often what was uncovered in our investigations has been confirmed by investigations in other countries. 
The development of the hybrid engine is the development of its elements namely, fuel blocks, injector and nozzle, and their integration into a total system. A brief description of the research and developmental effort in each of these components is presented in the following paragraphs. It must be noted that even though the development of each of these components is described separately, the programme did not progress in this way. At times, changes have been made in all the components and many times the development of one has caused changes in the others.

\subsection{Fuels}

First, it was necessary to make a solid fuel hypergolic with RFNA. Though in the initial stages some attempts were made to make the fuels along the lines of the Swedish efforts, they were abandoned when a new fuel was fortuitously discovered. This fuel is designated S22. It turned out to be extremely hypergolic with RFNA with ignition-delay values not greater than $50 \mathrm{~ms}$; the substance would retain hypergolicity even after it was melted and cooled. Its low melting point of $55^{\circ} \mathrm{C}$ was however an undesirable feature and so a search was made for another fuel with a higher melting point. Guided by chemical logic based on the structure of S22, another fuel designated S26 was developed. This had equally good hypergolic properties, and a melting point of $145^{\circ} \mathrm{C}$. However, it would not retain hypergolicity after melting presumably because its decomposition temperature is so close to its melting temperature; so that while heating the substance, the decomposition temperature would invariably be reached.

These fuels were first characterised for their ignition delay. Several studies (Shyamsukha 1974; Nandakumar 1977) have been conducted on the dependence of ignition delay on ambient temperature and pressure. Figure 4 shows the apparatus used in these tests. A partial set of results on the S22-RFNA system is seen in figure 5 . It is possible to obtain approximately the limits of safe operation (in terms of altitude)

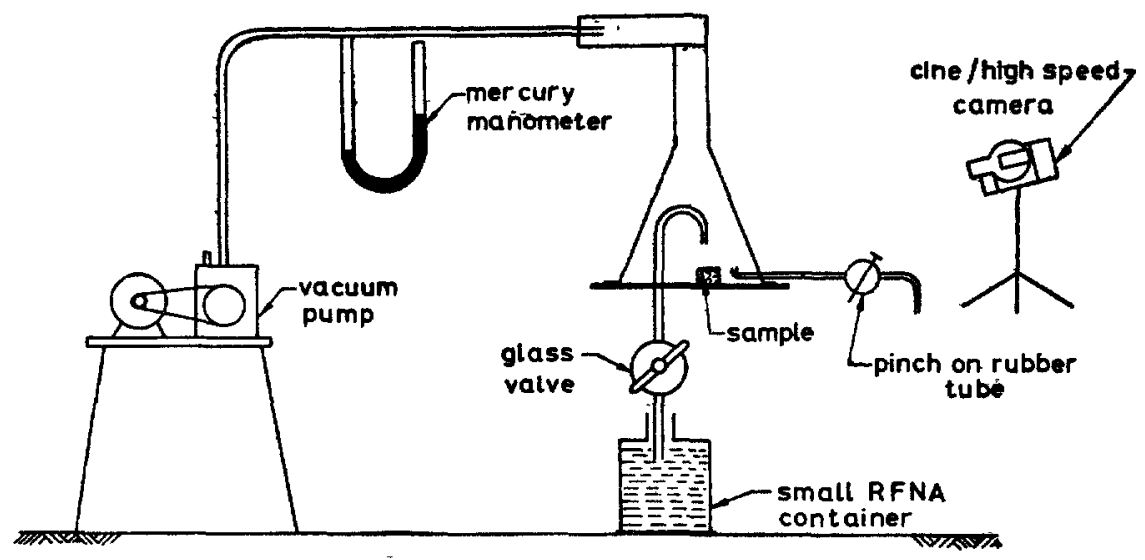

Figure 4. Ignition delay apparatus for low pressure/temperature experiments. The sample coated with melted $\mathbf{S 2 2}$ is kept below the tip of the jet inside the conical funnel connected to the vacuum pump. The rubber tube with pinch cock is used to regulate the level of pressure. The cine camera is started and the glass valve is opened. The oxidiser is sucked with the glass tube by the differential pressure. The rest of the events including the jet impingement on the surface of fuel and eruption of flame are followed by the camera. 


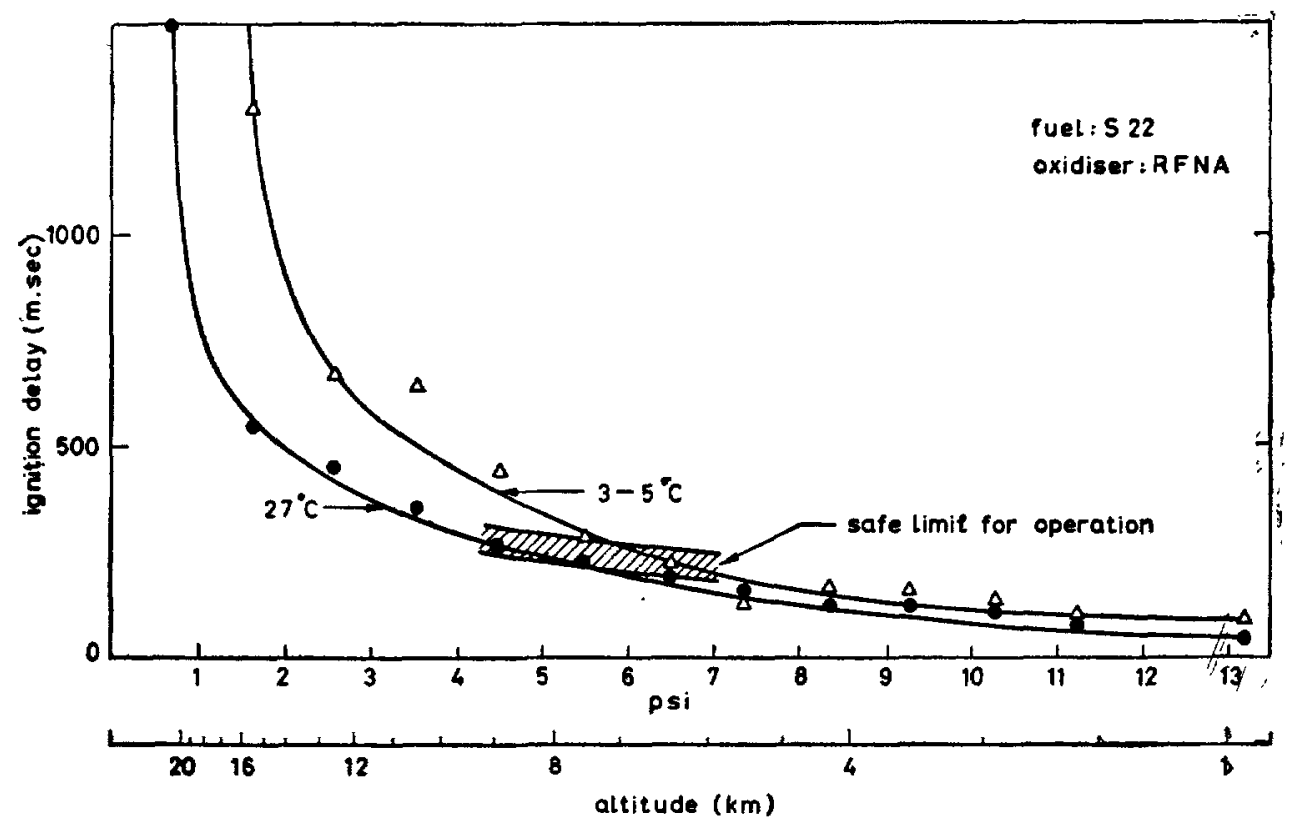

Figure 5. Results of ignition delay with ambient pressure and temperature. The altitude in the figure refers to pressure altitude.

if we note that experience at other places (see Anon 1964) suggests an upper limit of ignition delay of $250 \mathrm{~ms}$ for a safe start. The altitude turns out to be $6-7 \mathrm{~km}$.

Early firings were conducted using the above fuels, either pressed into grains or mixed, melted at $60^{\circ} \mathrm{C}$ and cast into blocks. The mechanical strength was increased by adding cellulose fibres into the composition during mixing. These firings showed severe oscillations in chamber pressure, but no ignition problem. At this stage, the work of Schmücker (1972) suggested that the injector end should have ' hard ' blocks, as the oscillations were thought to be caused by lack of 'hardness' in the block. It was, therefore, considered appropriate to integrate the fuel powder into the matrix of the polymer. These fuels turned out to be chemically so active that the polymerisation process was inhibited when the pre-polymer was mixed even with traces of the fuel ( $\mathbf{S 2 2}$ or $\mathbf{S 2 6}$ ) let alone large quantities. So, the casting process was abandoned and the process of integrating them into rubber in rubber mills was sought. Here again only S26 could be used since curing (or vulcanising) was done at temperatures of $100-110^{\circ} \mathrm{C}$ and use of $\mathrm{S} 22$ with a melting point of $55^{\circ} \mathrm{C}$ caused several problems in making the blocks. Using this procedure a maximum loading of $90 \%$ of S26 in natural rubber was achieved.

A large number of tests have been carried out with $75 \% \mathrm{~S} 26$ loaded rubber (denoted R005). Loaded rubber of S26 (25\%,50\% and $85 \%)$ have been used in regression rate studies. Test firings with these blocks showed substantially reduced oscillations and therefore the practice of using these blocks is being continued even now.

\subsection{Injectors}

It was recognised right from the beginning that the injector must (i) help in achieving 
good atomisation, (ii) distribute the oxidiser uniformly over the perimeter and (iii) reach the receding fuel surface (Mukunda 1975). To accomplish these objectives, a swirl injector design was chosen. Though in the early stages a swirl injector with an orifice of $1.5 \mathrm{~mm}$, flow rate of $10-15 \mathrm{~g} / \mathrm{s}$ was used, injector orifices of $7 \mathrm{~mm}$ with flow rates of $150-200 \mathrm{~g} / \mathrm{s}$ were used in actual engine firings. Since very little experimental data on injectors of these sizes were available (note that gas turbine swirlers used orifices of $0.8-1.0 \mathrm{~mm}$ diameter in most cases), experimental data were sought to be generated locally (Raghavendra Rao 1977). An experimental rig for measuring coefficient of discharge, cone angle and air core of the swirl injectors was built for the purpose (see Raghavendra Rao 1977). Figure 6 shows the different kinds of swirl injectors used. The three types studied are (i) swirl chamber type, (ii) swirl plate type and (iii) helical type. Amongst these injectors, the swirl chamber is the most complicated and the helical type the least from the point of view of fabrication. The principles involved in the design of the injectors are outlined in Nekrasov (1968).

A number of tests including engine firing were conducted to study the performance of the injector (in terms of influencing combustion efficiency). One particular feature not discussed hitherto in literature concerns the effect of the material of the injector. The early injectors were made of stainless steel (SS) following the practice in liquid rocket engines. Subsequently, for quick fabrication, some injectors were made of commercial aluminium. These injectors showed consistently better performance (in terms of combustion efficiency) compared to those of SS. In order to establish this, engine firings were made on SS and aluminium injectors of identical geometrical characteristics. Table 6 shows the results confirming the earlier observation. The cause was traced to be the better heat transfer characteristics of aluminium, as can be noted from the fact that aluminium has almost five times the thermal conductivity of stainless steel. Apparently, RFNA is better beated along the path of the injector

(6a)
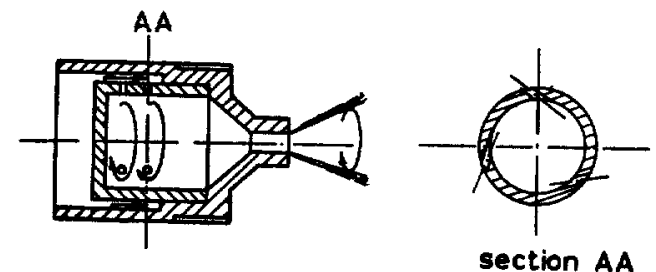

(6b)

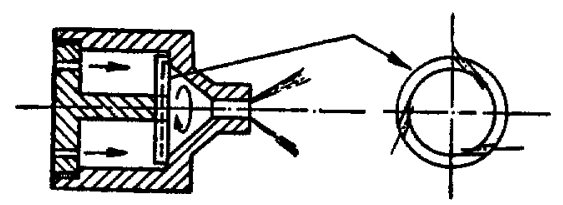

(6c)

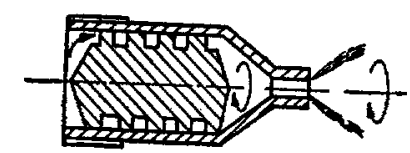

Figure 6. The various injectors. a. Swirl chamber type. b. Swirl plate type. c. Helical. The swirl chamber type has an inner part which has tangential holes made such that the liquid entering it has swirl imparted to it. The swirl plate injector has the inner part with tangential slots cut into its face. The inner part of the helical injector is simply a shaft with square threads cut on it. 
Table 6. Effect of injector on performance

\begin{tabular}{|c|c|c|c|c|}
\hline & \multicolumn{2}{|c|}{ Swirl injector characteristics } & \multirow{2}{*}{$\begin{array}{c}\text { Combustion } \\
\text { efficiency } \\
\eta(\%)\end{array}$} & \multirow{2}{*}{$\begin{array}{l}\text { Thermal } \\
\text { conductivity } \\
\mathrm{cal} / \mathrm{cm}\left(\mathrm{s}^{\circ} \mathrm{c}\right)\end{array}$} \\
\hline & $\begin{array}{l}c_{d} \text { coefficient } \\
\text { of discharge }\end{array}$ & $\begin{array}{c}\text { Cone angles } \\
\text { (degrees) }\end{array}$ & & \\
\hline Stainless steel & 0.18 & 95 & 60 & 0.062 \\
\hline Aluminium & $0 \cdot 17$ & 98 & 85 & 0.485 \\
\hline
\end{tabular}

in the aluminium injector and this facilitates quicker vaporisation and so leads to better combustion efficiency.

This feature was further verified by engine tests conducted with extended lengths of injector exposed to hot gases inside the combustion chamber. It was determined from several such experiments that for flow rates of the order of $300 \mathrm{~g} / \mathrm{s}$ (needed to obtain a $100 \mathrm{~kg}$ thrust) one needs a heating tube of about $35-38 \mathrm{~cm}$. This length was needed in spite of the heating of RFNA caused in the regeneratively cooled nozzle which was being used since 1975 . To obtain the length of heating tube consistent with the requirements of the injector, a special design shown in figure 7 and figure 8 (plate 1) was developed. The injector had also features for injector area variation thus providing variation in thrust. This injector has been used in more than a dozen firings and has been found to give the desired flow with proper heating. There are still a few problems associated with variable area device and further developments are in progress.

\subsection{The nozzle}

Early firings used an uncooled nozzle made of mild steel or in some cases stainless steel with throat inserts of graphite or mild steel. It was found that in firings where

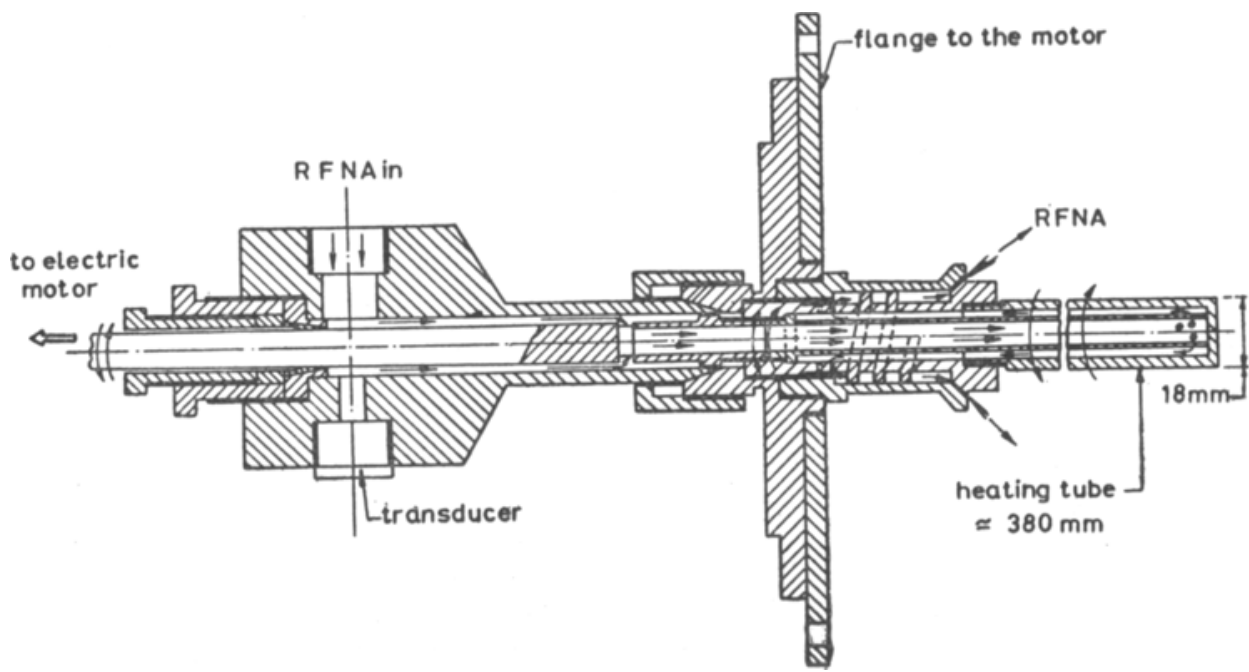

Figure 7. Details of the annular injector with heating tube and possibility for area variation. 
combustion was good, the nozzles invariably had melted at the throat and flowed. The graphite blocks would invariably crack after 6-7 s of firing. Hence it was considered better to use a regeneratively cooled nozzle $(\mathrm{RCN})$ to protect the throat. The passage of RFNA through the RCN would also help the heating of RFNA and hence lead to better combustion efficiency. Another reason for using RCN was that it would be necessary to go in for long burn durations. A number of tests have been conducted on the total system including the use of an RCN. Figure 9 (plate 1) and figures 10 and 11 (plate 2) show the two types of RCN used in the firings and figure 12 shows the method of fabricating the nozzles. The helical type was conceived first, designed, fabricated and tested in about a dozen firings. In most of these firings the nozzle throat would burn out after 8-10s of firing. In order to investigate this theoretically a computer program was written to determine the gas-side wall temperature $\left(T_{w g}\right)$. These calculations based on Bartz (1968) relations for heat transfer showed th at the nozzle was safe. $T_{\mathrm{wg}}$ was predicted to be about $1200^{\circ} \mathrm{K}$, whereas in the firing the temperature must have exceeded $1780^{\circ} \mathrm{K}$ (the melting point of mild steel). Several reasons were proposed and investigated (Paul et al 1977). The most probable turned out to be gas phase unsteadiness. Another reason could be the reduction in heat transfer coefficient due to passage through a helical path. The first cause was found more probable because the uncooled parts of the nozzle had eroded more in firings

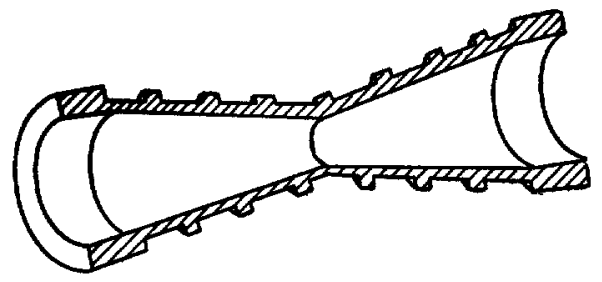

$$
\begin{aligned}
& \text { single block } \\
& \text { machined }
\end{aligned}
$$
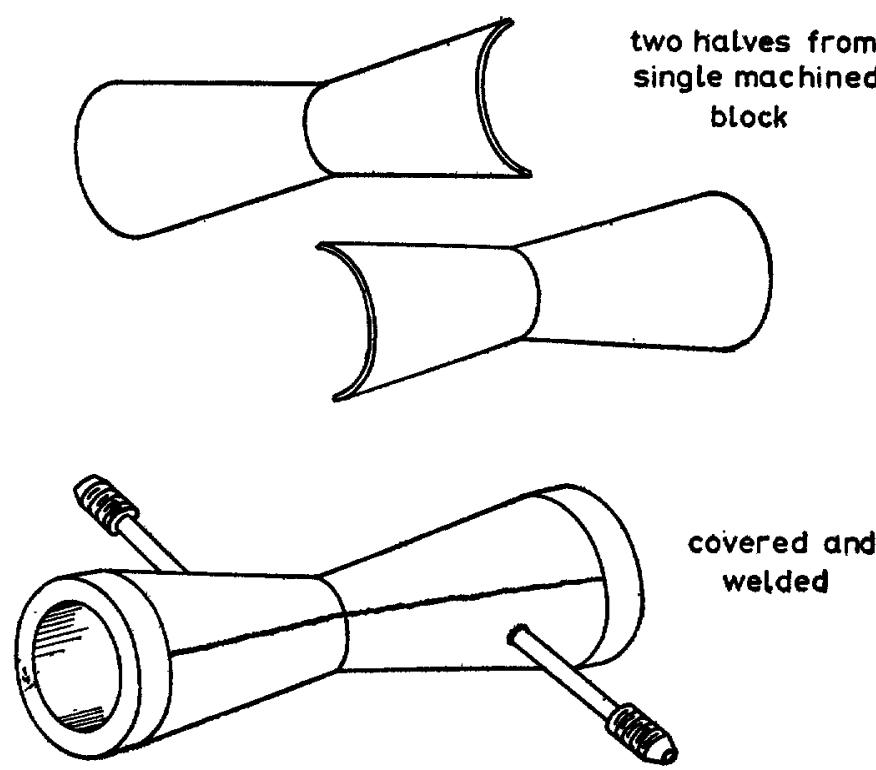

Figure 12. Regeneratively cooled nozzle and how it is made.

Proc. C-6 

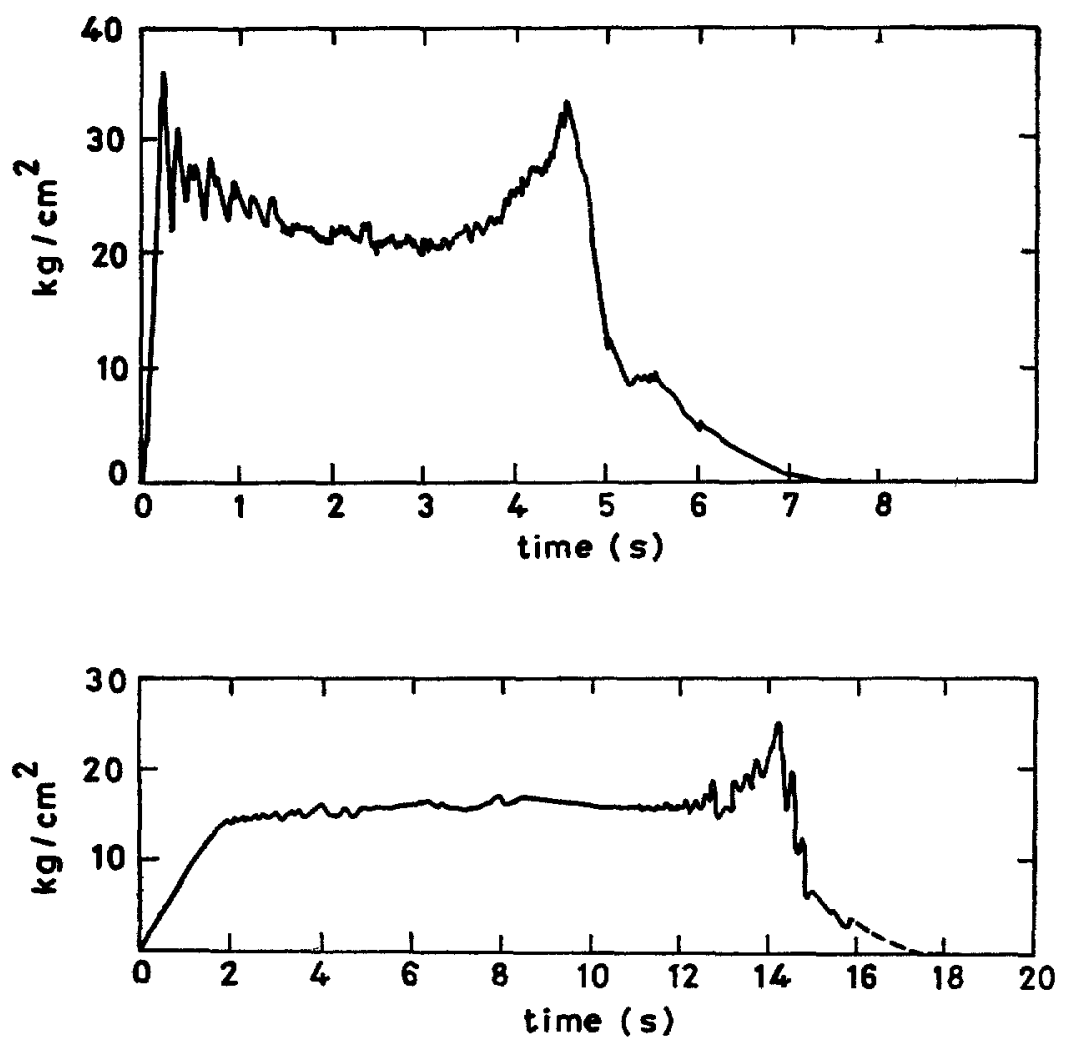

Figure 15. Pressure time traces of firing using the above nozzles. Note the upper trace corresponds to the nozzle with larger erosion (left).

which contained larger oscillations. Figures 13 and 14 (plate 3 ) show the cut nozzles in two firings where one of them has eroded much more at the inlet; Figure 15 gives the corresponding trace indicating more oscillations. Studies of Feiler \& Yeager (1962) show that there is $40-50 \%$ increase in the mean heat flux when the oscillations are in the range of $30-40 \mathrm{~Hz}$, a region where oscillations have been found in our test firings also. Thus efforts to remove the oscillations would make the nozzle safe. Further, to avoid the problem of possible reduced heat transfer coefficient in helical passage flow, a new design which, incidentally, is simpler to fabricate was thought of (see figure 10, plate 2). Tests with these have shown safe operation for burn-times as much as $15-17 \mathrm{~s}$. This nozzle design is now being used in all the tests.

\subsection{Regression rate studies}

The parameters of the regression rate law $r_{n}=a G^{n}, a$ and $n$ have to be determined from experiments to enable design calculations to be made. To this end the weight loss of fuel blocks was obtained in firings conducted with many motors (six in our case) under identical conditions, but for different burn-times. Figure 16 shows the details of the facility used for regression rate measurement. The parameters monitored during a test are chamber pressure, initial and final weights of fuel block and the weight of the oxidiser. These data are subjected to analysis to obtain the 


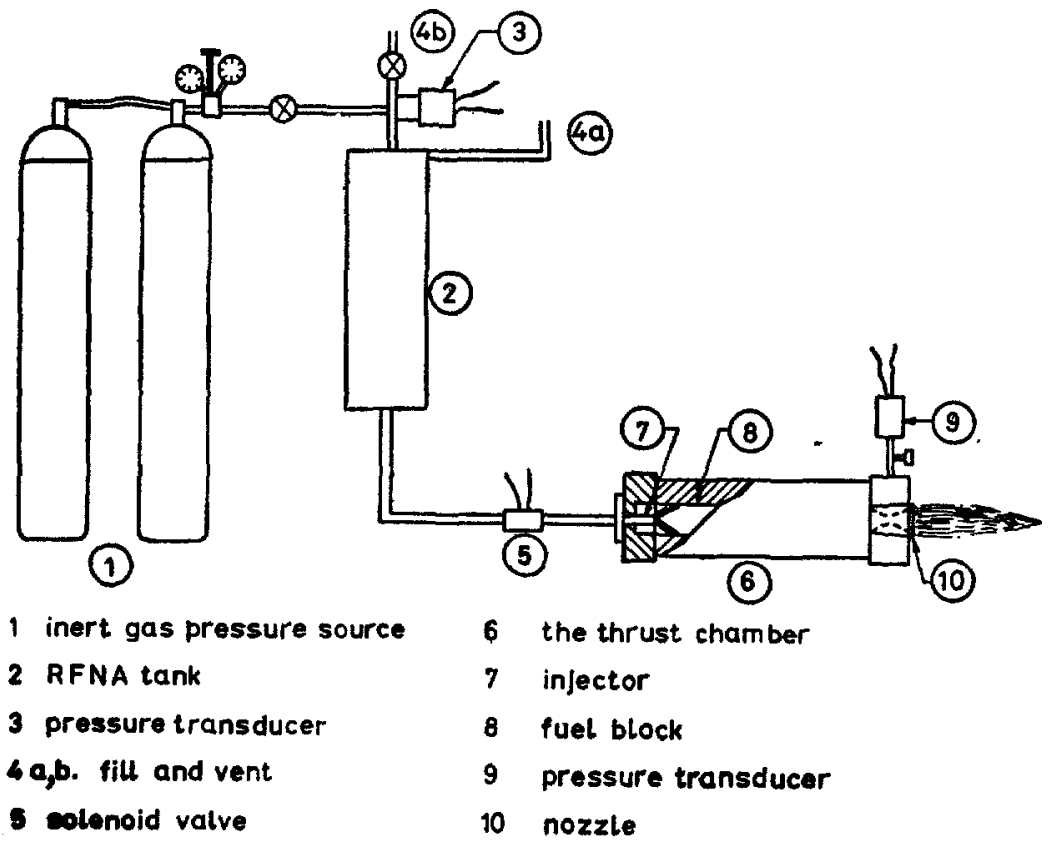

Figure 16. Schematic of the facility for tests on regression rate

Table 7. Results of regression rate

\begin{tabular}{ccc}
\hline$\% \mathrm{~S} 26$ & $\begin{array}{c}P_{c} \\
(\mathrm{~atm})\end{array}$ & $\begin{array}{c}(G)^{\frac{a}{0.5}} \times 10^{3} \\
(\mathrm{~cm} / \mathrm{s})\end{array}$ \\
\hline 85 & 13 & 25.9 \\
75 & 25 & 20.5 \\
75 & 7.5 & 16.8 \\
50 & 19.0 & 15.6 \\
25 & 7.9 & 10.6 \\
\hline
\end{tabular}

values of $a$ and $n$. From the present experiments it has not been possible to fix a value for $n$. More tests of longer burn duration are planned to evaluate $n$. Since $n$ could either be 0.5 or 0.8 depending on whether flow is laminar or turbulent, a value of $n=0.5$ was chosen for correlations (invoking Barrere \& Moutet 1967). Table 7 shows some of the results of the regression rate study. It is seen from these that $a$ does not change beyond a pressure of 12 atm. This implies that combustion is diffusion limited beyond $12 \mathrm{~atm}$. It can also be noticed that the percentage content of S26 has a significant effect on the regression rate. This is primarily because of significant heterogeneous reactions between the RFNA vapour and $\mathbf{2 6}$ in the fuel block. More fundamental studies are in progress to elucidate the details of reaction kinetics in the hybrid regression rates.

\subsection{General remarks}

The characteristic velocity ( $c^{*}$ or $c^{*} / g$ ) of the R005-RFNA system has been evaluated in several tests. Table 8 shows the results. This table also shows the combustion 
Table 8. Results of performance

\begin{tabular}{rccc}
\hline$O / F$ & $\begin{array}{c}c^{*} / g \\
(\mathrm{~s})\end{array}$ & $\begin{array}{c}\text { Combustion } \\
\text { efficiency } \\
(\eta \%)\end{array}$ & $\begin{array}{c}I_{\mathrm{sp}}=c^{*} / g \times C_{F}, \\
\mathrm{CF}\end{array}$ \\
\hline $5 \cdot 35$ & $126 \pm 2$ & $90 \pm 2$ & $189 \pm 3$ \\
$3 \cdot 74$ & $150 \pm 2$ & $96 \pm 2$ & $225 \pm 3$ \\
5.0 & $136 \pm 2$ & $96 \pm 2$ & $204 \pm 3$ \\
$C_{F}$ is taken 1.5 for a pressure ratio of 30 and area ratio of 5.6 for \\
ambient pressure 1 atm.
\end{tabular}

efficiency and estimated specific impulse. It is seen that values of combustion efficiency as high as $96 \%$ have been obtained and the estimated specific impulse compares well with those of intermediate energy solid propellants (like PBAN-based propellants). The use of a larger amount of rubber in the place of S26 is expected to enhance the specific impulse to a level comparable to that of high energy solids.

Todate, among the seventy and odd firings on the $100 \mathrm{~kg}$ engine there have been three explosions, two of them in the early periods when S22 and S26 had not yet been developed. The third occurred recently due to the mechanical failure of what turned out to be a poorly fabricated joint. Barring these three, all the other firings have been smooth. In many of these tests fuel blocks of $80 \mathrm{~mm}$ length were pushed into the motor without any serious regard for joining the blocks. And yet there was no untoward feature in the pressure-time trace for reasons suggested in $\S 2.3 \mathrm{c}$. Figure 17 (plate 4) shows the engine firing on the test stand.

This kind of development would have been impossible with the resources and manpower available at an academic institution, had the subject of development been either a solid or a liquid system. The three factors which have contributed to the fairly rapid development are (i) the relatively low level of technology needed in making the fuel, (ii) the almost complete absence of explosions and (iii) the low cost of chemicals used.

Studies are now being conducted (i) to enhance the fundamental understanding of regression rates of various fuels, (ii) to understand the structure of oscillations in the chamber pressure and the ways in which these are overcome and (iii) to further develop the injector to obtain variable thrust.

\section{Future prospects}

It is pertinent to recall from $\S 3.4$ that the development of hybrids is particularly attractive in situations where the development of other propulsion systems for large thrust (i) has not already been completed, (ii) is being currently undertaken or (iii) is being planned. As noted earlier, the cost of development of hybrids for a relatively small variable thrust engine is one-tenth of that for the development of liquid engine. Now, even if the cost difference is not one-tenth, but one-half to one-third, the saving would be very significant. Further, one must note that the development is likely to be faster because of various factors discussed earlier, particularly in $\S 4.5$. Consequent upon these factors, it seems that a hybrid propulsion system has greater 
possibilities for many applications. This does not mean that a hybrid propulsion system offers a solution to every problem of propulsion. This fact has already been noted in $\S 2.5$. But there are areas like high thrust engines for large duration where it appears highly suited (as argued by Ordahl 1964). Some calculations regarding the feasibility of such a system for engine thrusts of $3,000,20,000$ and $40,000 \mathrm{~kg}$ for burn durations of $50 \mathrm{~s}$ have been made and the likely new problem areas identified (Mukunda 1977).

For most applications in space and some in weapon systems, the most promising oxidiser appears to be the liquid oxygen. Though cryogenic handling is an additional problem, this oxidiser is most abundant and powerful. In fact another developmental project which uses liquid oxygen as the oxidiser is now in progress at the Indian Institute of Science.

\section{Conclusions}

A review of the earlier work on hybrid propulsion systems has been presented from the point of view of research and development. The development work in other countries, particularly USA, suggests that both small-impulse (or thrust burn-time) and large-impulse systems are technically feasible and economically viable. The reasons for overlooking the development of the hybrid propulsion system in other countries have been brought out to be more historical than technical. The progress in its development is argued to be more rapid than in (i) solids because of the relatively low explosion hazard and simplicity of fuel and (ii) liquids because of its simplicity as a system. The research and development work on a $100 \mathrm{~kg}$ rocket carried out at the Indian Institute of Science appears to support each of the above conclusions.

The work described here has been financed by the Aeronautics Research and Development Board. Many members have contributed to this work. Dr M Chanda, a co-investigator on this project, was responsible for the development of the fuel S22. Dr Y P Saradhy used chemical intuition to produce S26. Dr B N Raghunandan has been involved in many phases of the development and the instrumentation for the tests. Dr A G Marathe has contributed to several decisions during the development phase. Dr Raghunandan and Mr T Venkateswara Rao have made many useful criticisms on this manuscript. Thanks are due to the authorities of the Aeronautics Research and Development Board for permission to publish this paper.

\section{References}

Ankarsward B 1966 World aerospace systems 2 362; also 1964 Interavia p 1839

Anon 1964 Design study of hybrid hover motor-final report, Vol 1 Technical Contract No. NAS 7-143 17 January

Anon 1967 Aerospace yearbook (Sparton) 45th ed.

Barrere M \& Moutet A 1967 Int. Sci. Technol. (August) p 64

Bartz D R 1968 Advances in tactical rocket propulsion ed S S Penner AGARD Conf. Proc. No. 1, p. 291 
Duban P 1968 L'Aeronaut. L'Astronaut. p. 49

Feiler E E and Yeager E B 1962 Effect of large amplitude on heat transfer, NASA TR R-142

Gany A and Timnat Y M 1972 Is. J. Technol. 1085

Judge J F 1964 Missiles Rockets 1531

Karnesky A L and Colucci S E $1975 J$. Spacecr. Rockets 1233

Kit B and Evered D S 1960 Rocket propellant handbook (New York: Macmillans)

Magnusson U 1966 World Aerosp. Syst. p. 50

Marxman G and Gilbert M 1963 Ninth symposium (international) on combustion (New York: Academic Press) p. 371

Marxman G A and Woolridge C E 1968 Advances in tactical rocket propulsion ed S S Penner, AGARD Conf. Proc. No. 1, p. 420

Mastrolia E J and Klager K 1969 Propellants manufacture, hazards and testing eds C Boyars and K Klager (Washington: Am. Chem. Soc.) p. 159

Mukunda H S 1975 Some thoughts on injector designs for hybrid rocket motors, Internal Report, HRM 009

Mukunda H S 1977 Hybrid rocket propulsion as a new possibility, Internal Report, HRM 012

Nachbar W 1964 Missiles Rockets 1515

Nandakumar V L 1977 Aging studies on ignition delay of hybrid fuels hypergolic with RFNA at low pressures and temperatures, M. E. thesis, Indian Institute of Science, Bangalore

Nadaud L and Baisini J 1966 La Recherche Aerospatiale No. 115, p. 45

Nekrasov B 1968 Hydraulics (Moscow: Mir Pub.)

Ordahl D D 1964 Missiles Rockets 1511

Ordahl D D and Bae W E 1965 Hybrid propulsion development, Air-Review, Belgium, p. 441

Paul P J, Jain V K, Mukunda H S and Chanda M 1977 Studies on hybrid rocket motor, Paper presented at the Gas Turbines Symposium, GTRE, Bangalore

Perrson L 1970 Space engineering ed. G A Partel (Holland: Reidel) p. 338

Raghavendra Rao 1977 Studies on swirl type injectors with reference to hybrid rocket engines, M.Sc. thesis, Indian Institute of Science, Bangalore

Schmucker R 1972 Hybrid rocketantriebe (Munchen, Germany: Wilhelm Goldman, Verlag)

Schmucker R 1972 Development of a small hybrid rocket engine, 22 IAF Kongre B Brussels

Schrucker R H and Schauer W M 1974 Barbarella-the experimental hybrid rocket, Report LRT-TUM-TB21-Warr

Shyamsukha M C 1974 Ignition delay studies of hybrid fuels hypergolic with RFNA with drop tester M.E. thesis, Indian Institute of Science, Bangalore

Thaper K K, Saradhy U P and Jain V K 1977 Combust. Flame 29325

Tischler A O 1964 Fuels and new propellants, Proc. Conf., Milan, ed. E C Caxi (New York: Pergamon)

Verdier C 1970 La Recherche Aerospatiale No. 137, p. 181 
Plate 1

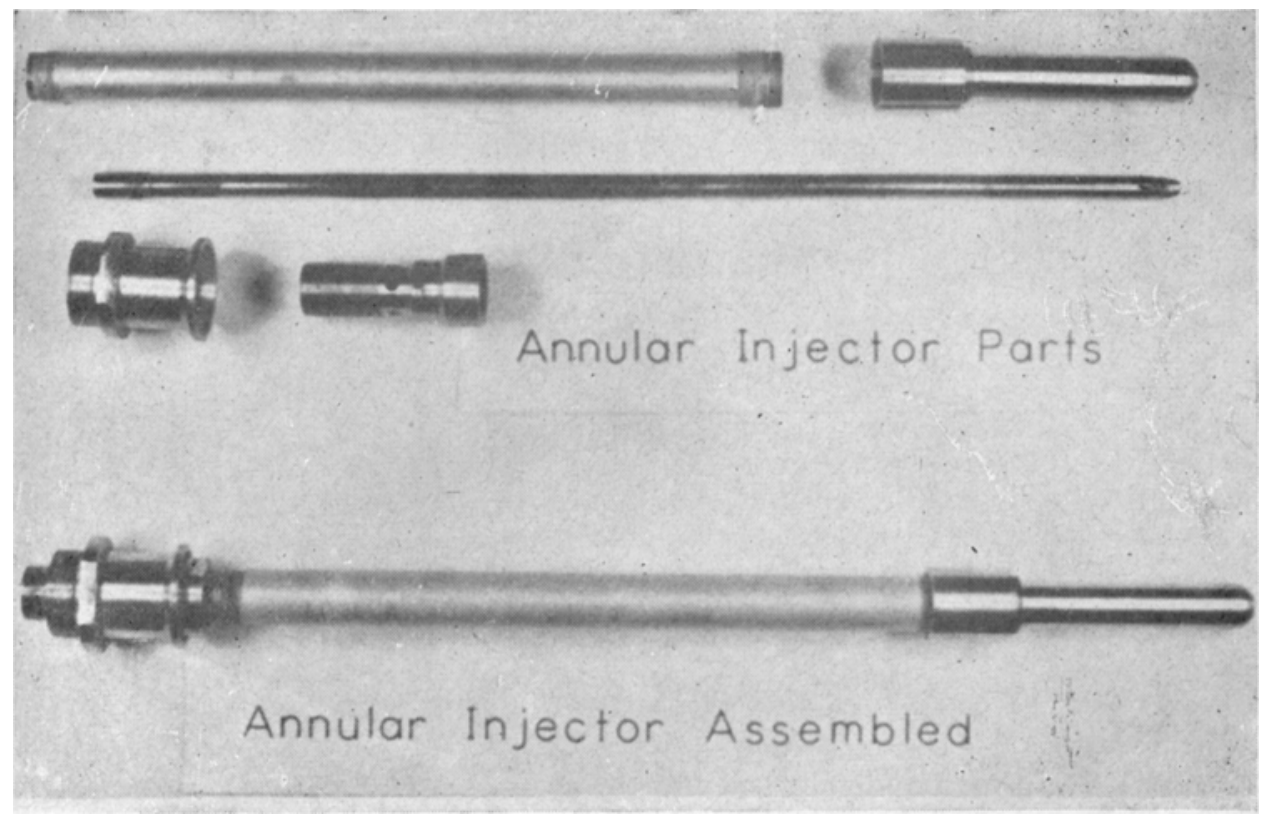

Figure 8. Details of the annular injector with heating tube and possibility for area variation

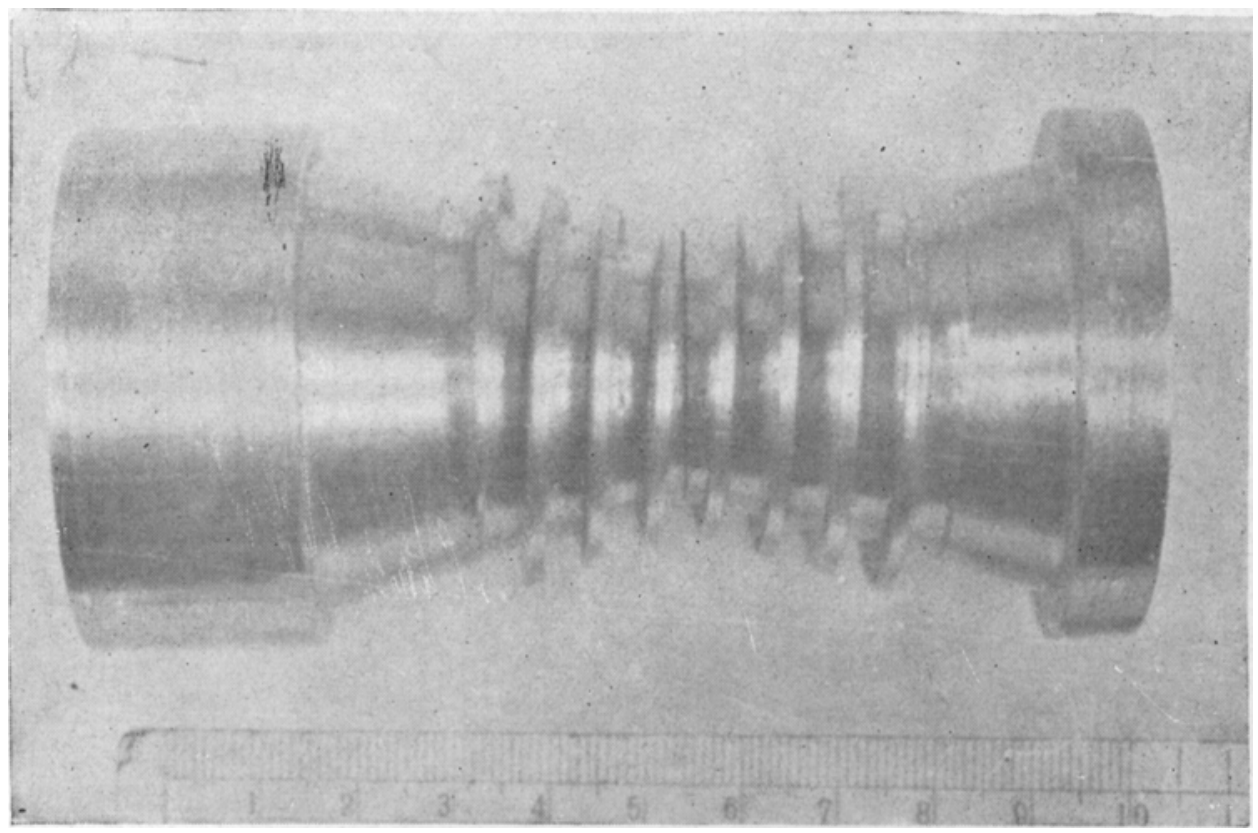

Figure 9. Regeneratively cooled nozzle. Inner part with helical passage. 
Plate 2

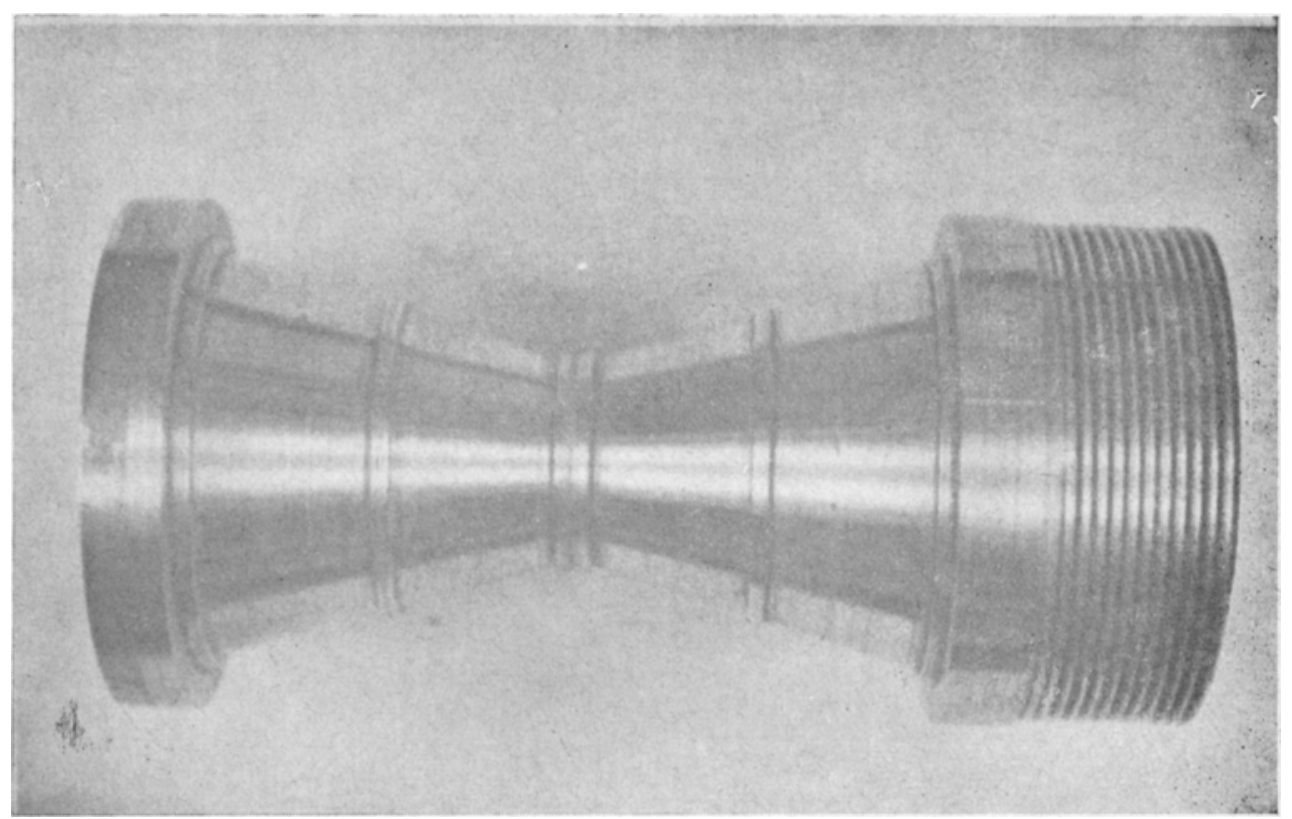

Figure 10. Regeneratively cooled nozzle. Inner part with hollow uniformly accessible passage.

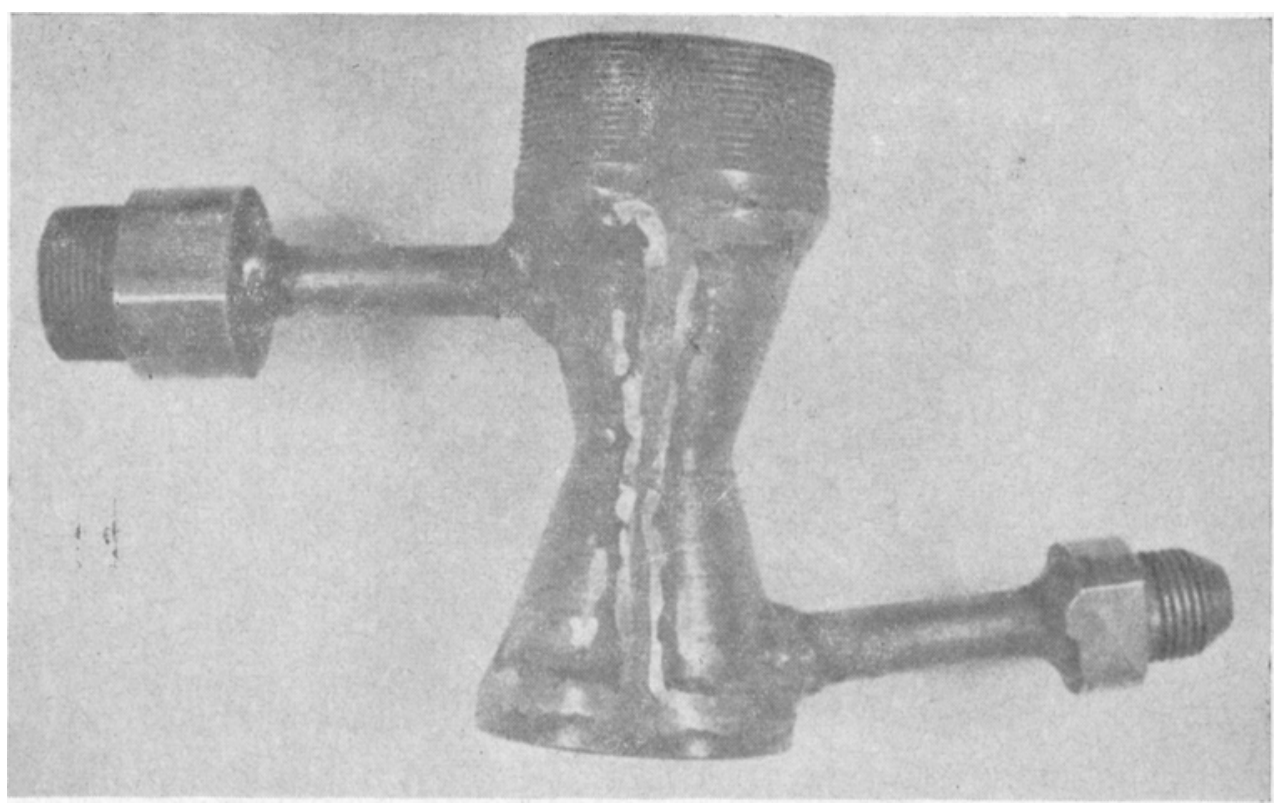

Figure 11. The finished nozzle. 
Plate 3

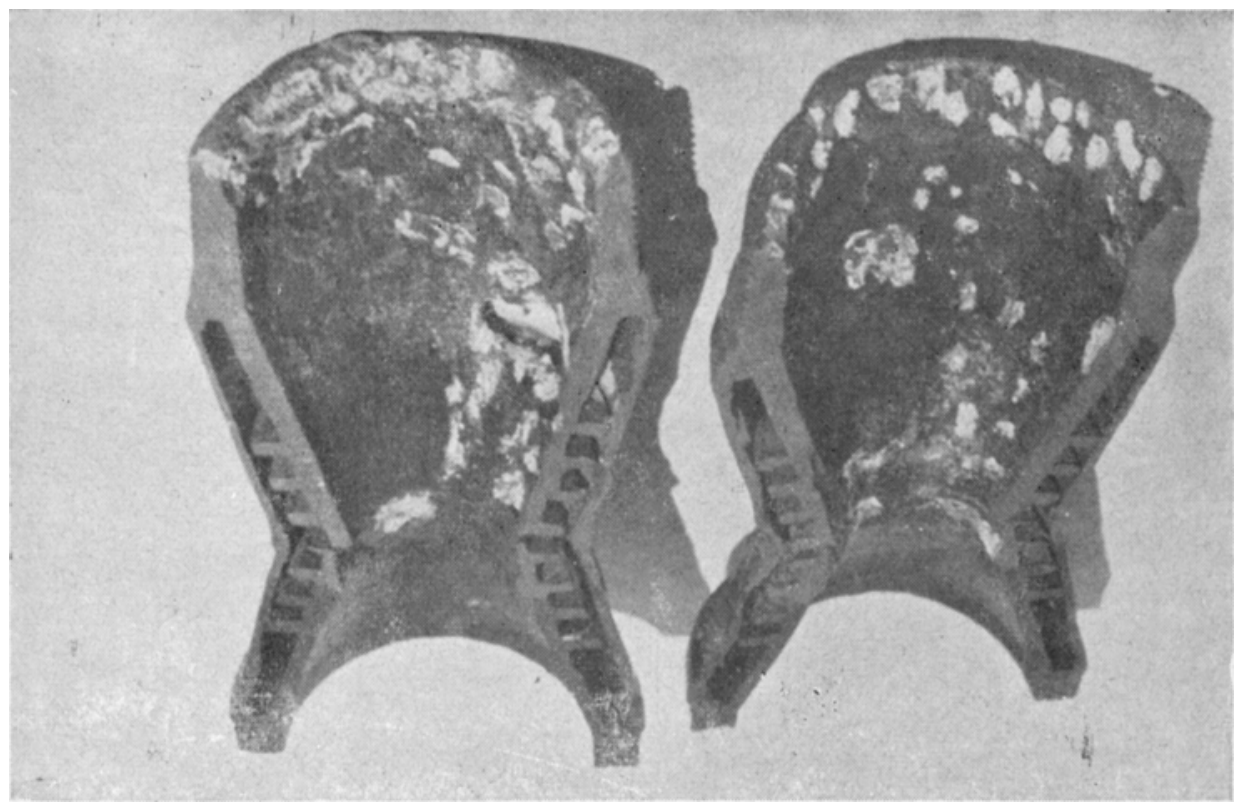

Figure 13.

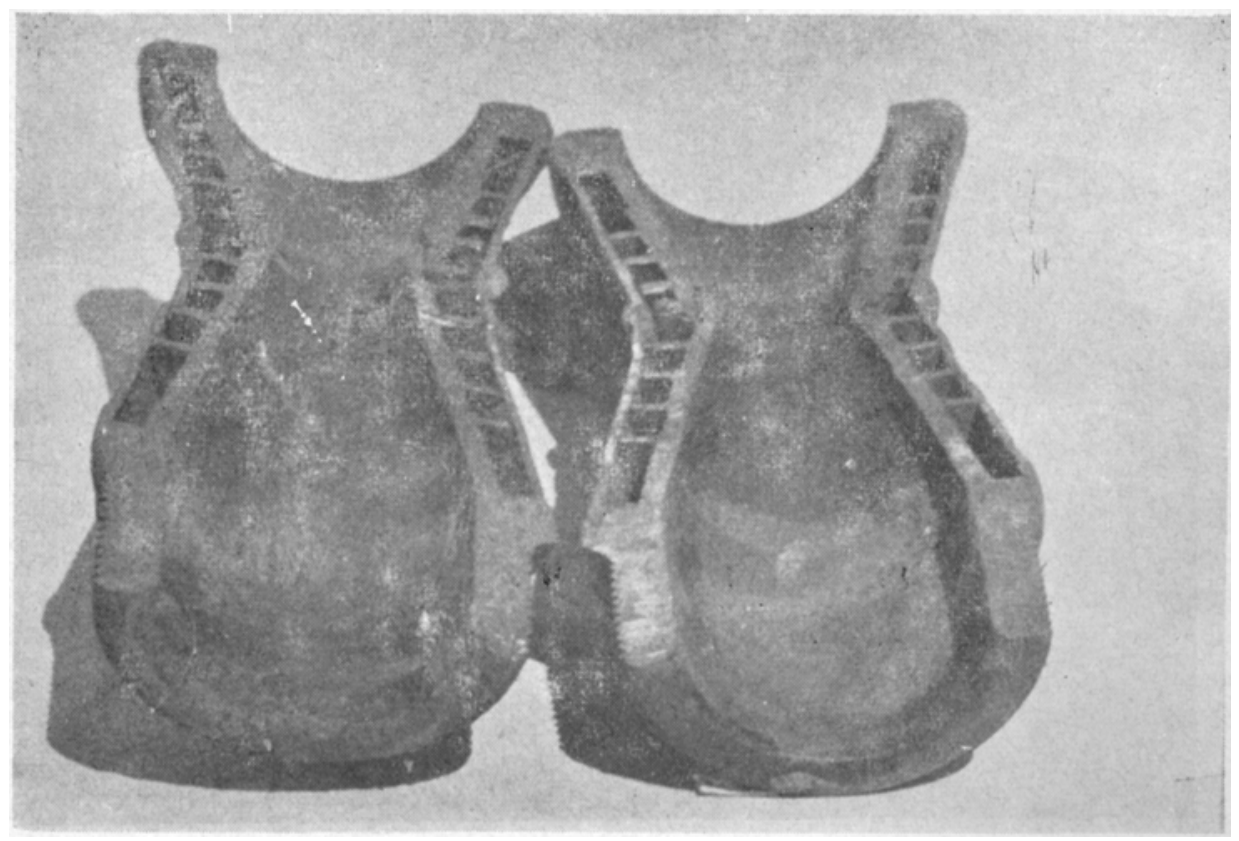

Figure 14.

Figures 13 and 14. Eroded nozzles cut after firing. 
Plate 4

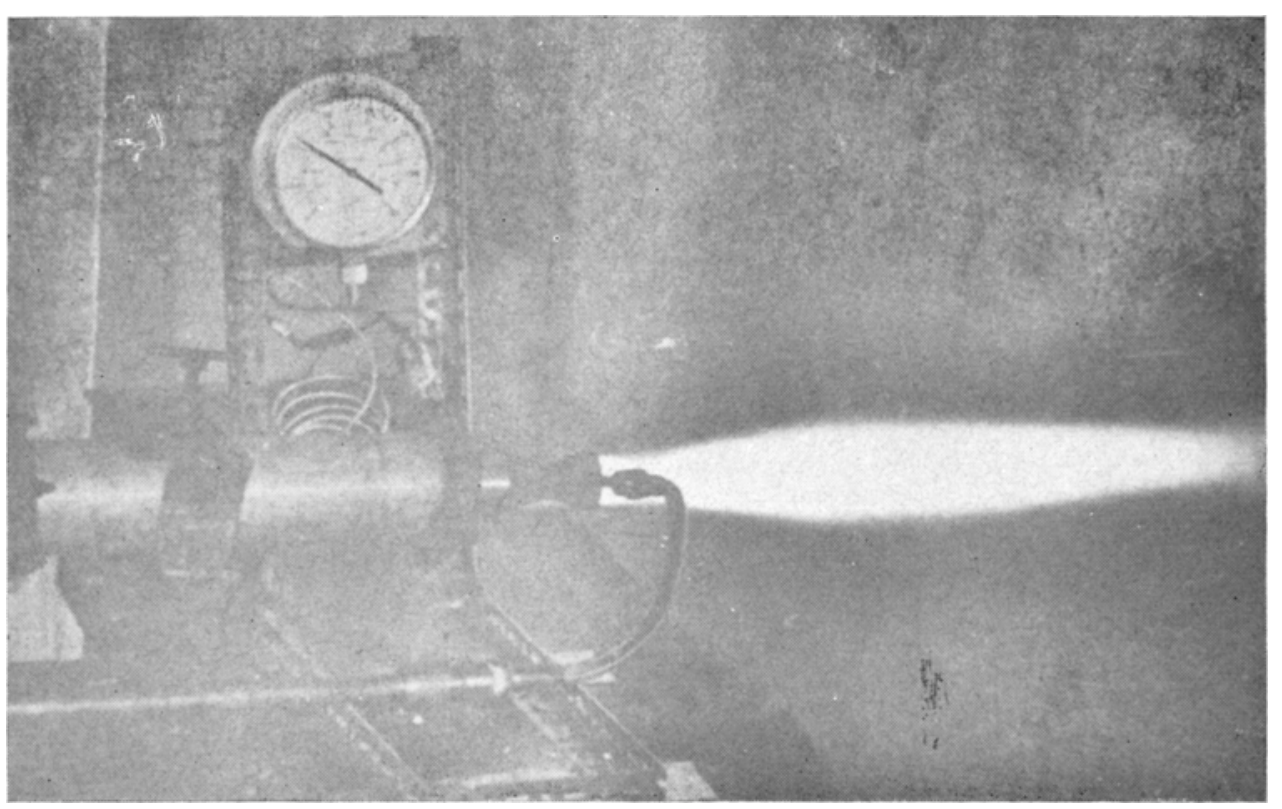

Figure 17. Firing of the engine. 